\title{
Population-based improvement heuristic with local search for single-row facility layout problem
}

\author{
SOUMEN ATTA ${ }^{1, *, \$}$ (D) and PRIYA RANJAN SINHA MAHAPATRA ${ }^{2}$ \\ ${ }^{1}$ Indian Institute of Information Technology (IIIT) Vadodara, Gandhinagar Campus, Sector 28, Gandhinagar, \\ Gujarat 382028, India \\ ${ }^{2}$ Department of Computer Science and Engineering, University of Kalyani, Kalyani 741235, India \\ e-mail: soumen_atta@iiitvadodara.ac.in; priya@klyuniv.ac.in
}

MS received 16 July 2017; revised 1 April 2019; accepted 27 August 2019

\begin{abstract}
The Single-Row Facility Layout Problem (SRFLP) is a well-known combinatorial optimization problem. The objective of SRFLP is to find out the arrangement of facilities with given lengths on a line so that the weighted sum of the distances between all pairs of facilities is minimized. This problem is known to be NPhard. Hence, a population-based improvement heuristic algorithm with local search is presented in this article to solve SRFLP. The proposed algorithm works well also for the Single-Row Equidistant Facility Layout Problem (SREFLP), where the length of each facility is equal. The computational efficiency of the proposed algorithm is checked with the instances of sizes ranging from 5 to 300 available in the literature for SRFLP and SREFLP. The obtained results are compared to those from different state-of-the-art algorithms. The proposed algorithm achieves best known solutions to date for every instance considered in this article in reasonable computational time.
\end{abstract}

Keywords. Single-row facility layout problem (SRFLP); single-row equidistant facility layout problem (SREFLP); population-based heuristic; improvement heuristic; local search.

\section{Introduction}

The Single-Row Facility Layout Problem (SRFLP) was first introduced by Simmons [1]. Given a set of facilities with different lengths, SRFLP is the problem of finding an arrangement of facilities in a single row such that the weighted sum of the distances between all pairs of facilities is minimized [1-13]. SRFLP is a well-studied combinatorial optimization problem and it is a special case of the Weighted Betweenness Problem, which is again a special case of the Quadratic Ordering Problem [14]. When each facility has unit length, SRFLP is known as the Minimum Linear Arrangement Problem (MinLA) [6]. Another special case of SRFLP is the Single-Row Equidistant Facility Layout Problem (SREFLP) [14, 15], where the length of each facility is equal. SREFLP is sometimes called as the one-dimensional machine location problem [16] or the linear machine-cell location problem [17].

Many applications of SRFLP can be found in [1, 2, 4]. The arrangement of rooms in hospitals and supermarkets [1],

\footnotetext{
${ }_{\mathrm{S}}^{\$} \mathrm{~S}$. Atta is currently on leave from IIIT Vadodara and is now associated with the Faculty of Informatics, Masaryk University, Botanická 68a, Brno, Czech Republic as a Postdoctoral researcher.
}

*For correspondence

Published online: 19 October 2019 arrangement of machines in flexible manufacturing systems [4], assignment of computer disk cylinders to files [2], warehouse layouts [2], arranging books on a shelf in a library [2], the assignment of planes at an airport terminal [5], etc. can be modelled as SRFLP. A comprehensive review on SRFLP can be found in [9]. Surveys on different computational modelling approaches used to solve SRFLP can be found in [18, 19]. Recent developments on SRFLP over the last one and half decades can be found in the survey articles [20, 21].

In this article, a population-based improvement heuristic with local search is proposed. The proposed algorithm maintains a set of candidate solutions, known as population, and tries to improve each candidate solution using different local search techniques. The proposed algorithm can solve both SRFLP and SREFLP instances, and the performance of the proposed algorithm is compared to those of different exact algorithms based on mathematical programming $[14,22,23]$ and meta-heuristic algorithms $[8,10,13,24-26]$ for small-scale instances to the largescale instances of sizes ranging from 5 to 300. There are many real-world problems such as the maximal covering location problem [27], the uncapacitated facility location problem [28-31], the tool indexing problem [32], etc. related to SRFLP, which are NP-hard in general, and heuristic/meta-heuristic algorithms are developed for these problems. Hence, it is very obvious to use a population- 
based improvement heuristic algorithm to solve SRFLP that also falls under the class of NP-hard problems [3].

The organization of the article is as follows. A concise literature review on SRFLP is given in section 2. Different notations, terminologies used in this article and the problem definition are mentioned in section 3. In section 4, the proposed algorithm is described in detail. The results obtained using the proposed algorithm for different instances of both SRFLP and SREFLP and comparisons to the existing algorithms are discussed in section 5. Finally, section 6 concludes the article.

\section{Literature review}

A concise literature review is given in this section. Due to the enormous applications of SRFLP, it has gained considerable attention by the researchers of different fields since its inception by Simmons [1]. Moreover, SRFLP is known to be NP-hard [3]. Hence, different approaches have been used to solve SRFLP by many researchers. We can broadly categorize the different approaches used to solve SRFLP in two ways: exact methods and approximate methods. The different exact methods for solving SRFLP include branch-and-bound method [1, 23], integer programming [33-36], cutting plane method [37], dynamic programming [2], branch-and-cut [11], semidefinite programming [7, 19, 38, 39] and many more. The polyhedral studies of SRFLP can be found in [11, 40]. The different approximate methods include greedy like algorithm [4], iterative construction heuristics [4, 41, 42], tabu search [12, 43, 44], local search algorithms [10, 26], simulated annealing $[15,43,45,46]$, ant colony optimization [47], scatter search method [25, 48], particle swam optimization [49], genetic algorithm [8, 13, 24, 50], Greedy Randomized Adaptive Search Procedure (GRASP) with Path Relinking (PR) [51], etc. A hybrid algorithm was developed combining ant colony optimization (ACO) and particle swarm optimization (PSO) in [52]. An imperialist competitive evolutionary algorithm was proposed in [53]. These different methods are summarized in figure 1 .

\section{Notations, terminologies and problem definition}

The notations and terminologies used in this article are described in this section.

- The weight matrix $\mathcal{W}=\left(w_{i j}\right)_{n \times n}$ denotes the weight $w_{i j}$ of each pair $(i, j)$ of facilities, where $n$ is the total number of facilities available.

- The length matrix $\mathcal{L}=\left\{\ell_{1}, \ell_{2}, \ldots, \ell_{n}\right\}$ denotes the length $\ell_{i}$ of the facility $i$.

- The set of valid layouts, $\prod=\left\{\pi^{1}, \pi^{2}, \ldots, \pi^{p}\right\}$, where $\pi^{i}=\left\{\pi_{1}^{i}, \pi_{2}^{i}, \ldots, \pi_{n}^{i}\right\}$ is the permutation of $n$ facilities.

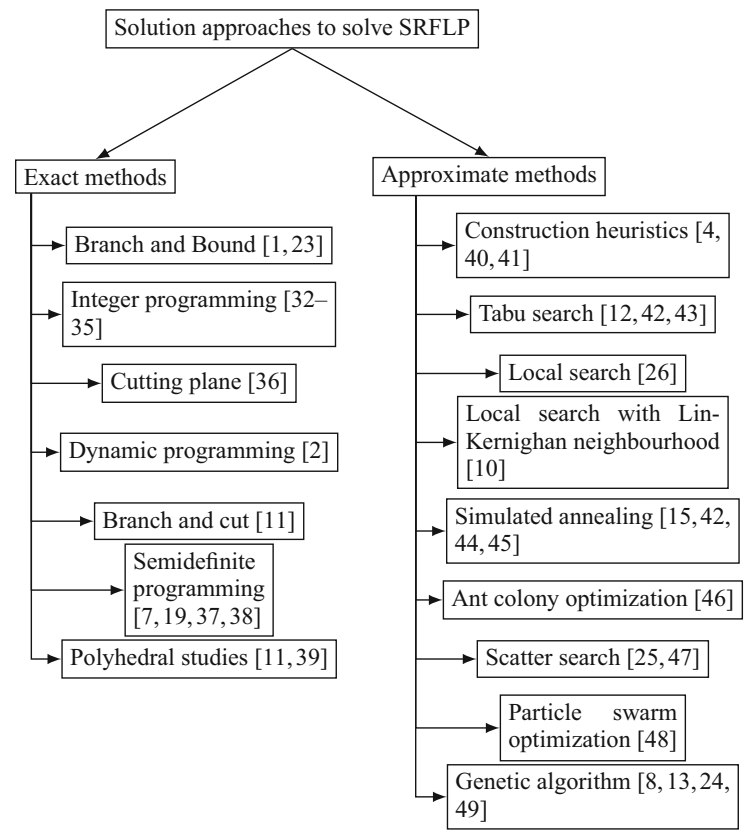

Figure 1. Solution approaches to solve SRFLP.

Here, the term valid implies that $\pi_{m}^{i} \neq \pi_{n}^{i}, \forall m \neq n$ in each $\pi^{i}$. For example, with $n=5$, one of the valid layouts may be $\{3,2,5,1,4\}$. We call each $\pi^{i}$ as a valid layout.

- Cost for each layout in $\Pi$ is denoted as $\mathcal{C}_{\prod}=\left\{C_{\pi^{1}}, C_{\pi^{2}}, \ldots, C_{\pi^{n}}\right\}$, where $C_{\pi^{i}}$ denotes the cost of the layout $\pi^{i}$. The cost of a layout $\pi$ is calculated as

$$
C_{\pi}=\sum_{1 \leq i<j \leq n} w_{i j} d_{\pi_{i} \pi_{j}}
$$

where $d_{\pi_{i} \pi_{j}}=\frac{1}{2}\left(\ell_{\pi_{i}}+\ell_{\pi_{j}}\right)+\sum_{i<k<j} \ell_{\pi_{k}}[11,9]$.

Using the afore-mentioned terminologies, the SRFLP can be now defined as follows: given a set $\{1,2, \ldots, n\}$ of $n$ facilities with the weight matrix $\mathcal{W}$ and the length matrix $\mathcal{L}$, the objective of SRFLP is to find out a layout $\pi$ with the minimum $\operatorname{cost} C_{\pi}$ among all the possible layouts $[9,11]$.

The following example illustrates SRFLP. Consider the following specifications of the weight matrix $(\mathcal{W})$ and the length matrix $(\mathcal{L})$ as shown in figure 2 with $n=5$ :

Note that in figure $2, \mathcal{W}$ is shown as an upper triangular matrix because $\mathcal{W}$ is a symmetric matrix, i.e., $w_{i j}=w_{j i}$,

$$
\begin{aligned}
\mathcal{W} & =\left[\begin{array}{ccccc}
0 & 2 & 10 & 10 & 14 \\
0 & 0 & 16 & 6 & 8 \\
0 & 0 & 0 & 2 & 10 \\
0 & 0 & 0 & 0 & 14 \\
0 & 0 & 0 & 0 & 0
\end{array}\right], \\
\mathcal{L} & =\left[\begin{array}{lllll}
1 & 1 & 1 & 1 & 1
\end{array}\right] .
\end{aligned}
$$

Figure 2. Weight matrix $(\mathcal{W})$ and length matrix $(\mathcal{L})$. 


$$
\begin{array}{rlrl}
d_{23} & =\frac{1}{2}(1+1)=1 & & \\
d_{25} & =\frac{1}{2}(1+1)+1=2 & & d_{35}=\frac{1}{2}(1+1)=1 \\
d_{21} & =\frac{1}{2}(1+1)+(1+1)=3 & & d_{31}=\frac{1}{2}(1+1)+1=2 \\
d_{24} & =\frac{1}{2}(1+1)+(1+1+1)=4 & & d_{34}=\frac{1}{2}(1+1)+(1+1)=3 \\
d_{51} & =\frac{1}{2}(1+1)=1 & & \\
d_{54} & =\frac{1}{2}(1+1)+1=2 & & d_{14}=\frac{1}{2}(1+1)=1 \\
C_{\pi} & =w_{23} d_{23}+w_{25} d_{25}+w_{21} d_{21}+w_{24} d_{24}+w_{35} d_{35}+w_{31} d_{31}+w_{34} d_{34}+w_{51} d_{51}+w_{54} d_{54}+w_{14} d_{14} \\
& =150 .
\end{array}
$$

Figure 3. Scheme of calculation to compute $C_{\pi}$.

$\forall i, j$. The objective of SRFLP is to find a valid layout $\pi$ so that the cost of $\pi\left(C_{\pi}\right)$ is minimized. Now, let us consider a valid layout $\pi=\{2,3,5,1,4\}$. A detailed calculation to compute $C_{\pi}$ is shown in figure 3 .

Note that in this article, the assignment operation $\left\{i_{1}, i_{2}, \ldots, i_{n}\right\} \leftarrow\left\{j_{1}, j_{2}, \ldots, j_{n}\right\}$ implies that $i_{1} \leftarrow j_{1}, i_{2} \leftarrow$ $j_{2}$ and so on. This kind of assignment operation is used in the proposed algorithm.

\section{Proposed heuristic}

In this section, a population-based improvement heuristic with local search is proposed. In this article, five different heuristic methods are developed to construct the proposed heuristic algorithm for SRFLP. One of the five heuristic methods is used to construct the initial population and they are all used to improve the solution obtained in any particular generation. The proposed algorithm tries to improve the solution over several generations and in each generation, different heuristic methods are used to improve the current available set of solutions. We will discuss the five proposed methods at first independently and after this we will discuss the main proposed algorithm for SRFLP. We will explain each of these five methods using the weight matrix $\mathcal{W}$ and the length matrix $(\mathcal{L})$ as shown in figure 2 .

\subsection{Weighted pair}

In this section, a heuristic method is described and we call this method as the Weighted Pair. The description of this heuristic method is given in Algorithm 1. It takes weight matrix $\mathcal{W}=\left(w_{i j}\right)_{n \times n}$, length matrix $\mathcal{L}=\left\{\ell_{1}, \ell_{2}, \ldots, \ell_{n}\right\}$ and a partial layout $\pi^{*}=\left\{\pi_{1}^{*}, \pi_{2}^{*}, \ldots, \pi_{k}^{*}\right\}$ where $0 \leq k \leq n$ and produces as its outputs a valid layout $\pi^{\circ}=$ $\left\{\pi_{1}^{\circ}, \pi_{2}^{\circ}, \ldots, \pi_{n}^{\circ}\right\}$ and cost of the layout $\pi^{\circ}$, i.e., $C_{\pi^{\circ}}$. Step 1 of Algorithm 1 computes the $\operatorname{rank} \mathcal{R}_{i j}(\forall i, j$ and $i<j)$ for each pair $(i, j)$ by evaluating $w_{i j}\left(\ell_{i}+\ell_{j}\right)$ and then by sorting in descending order. Note that $\mathcal{R}_{i j}=\mathcal{R}_{j i}, \forall i, j$ and $i \neq j$. Hence, we compute $\mathcal{R}_{i j}$ only for $i<j$. For example, consider the weight matrix $(\mathcal{W})$ and the length matrix $(\mathcal{L})$ as mentioned in figure 2. For these specifications, the rank $\mathcal{R}_{i j}$ is computed according to Step 1 and we show this as a triplet $\left(i, j, \mathcal{R}_{i j}\right)$ as follows:

$$
\begin{aligned}
& \left\{\left(i, j, \mathcal{R}_{i j}\right) \mid \mathcal{R}_{i j}=w_{i j}\left(\ell_{i}+\ell_{j}\right), \forall i, j \text { and } i<j,\right. \\
& \left.\quad \text { and } \mathcal{R}_{i j} \text { is sorted in descending order }\right\} \\
& =\{(2,3,32),(1,5,28),(4,5,28),(1,3,20), \\
& (1,4,20),(3,5,16),(2,4,12),(1,2,4),(3,4,4)\} .
\end{aligned}
$$

Now, we consider the case where partial layout $\pi^{*}$ is empty. Then $\pi_{1}^{o}=2$ and $\pi_{1}^{o}=3$, since $\mathcal{R}_{2,3}$ is the maximum. In this case, the final valid layout will be $\pi^{o}=\{2,3,5,4,1\}$ and the corresponding cost $C_{\pi^{o}}$ is 150 . Again, we consider a case where the partial layout $\pi^{*}$ is non-empty and say $\pi^{*}=\{4,5\}$. In this case, the for loop in line 6 will iteratively generate the final valid layout $\pi^{o}$. The next facility 1 will be added next since $\mathcal{R}_{5,1}\left(=\mathcal{R}_{1,5}\right)$ is the next maximum. Note that if $\mathcal{R}_{m n}=\mathcal{R}_{p q}$, then we consider $\mathcal{R}_{m n}$ for our evaluation if $m \leq p$ and $n \leq q$; otherwise we consider $\mathcal{R}_{p q}$ for our evaluation. Here, the final valid layout will be $\pi^{o}=\{4,5,1,3,2\}$ and the corresponding cost $C_{\pi^{o}}$ is 152 .

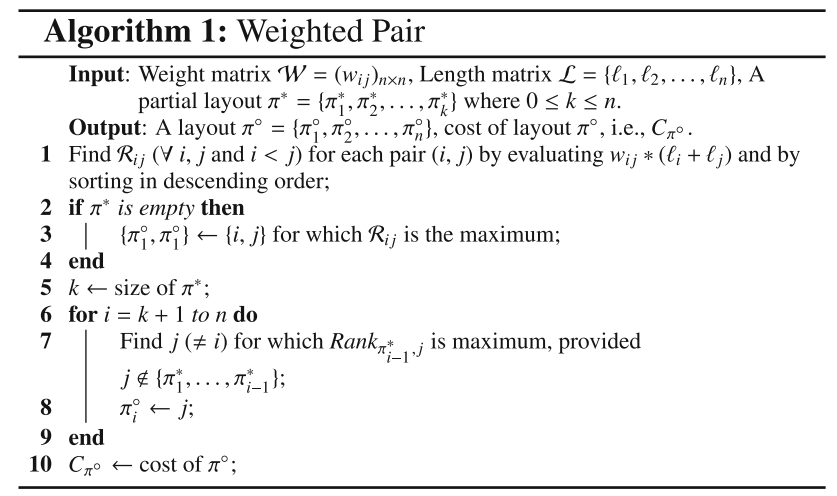

\subsection{Partial ordered replacement}

This heuristic method takes two valid layouts $\pi^{i_{1}}$ and $\pi^{i_{2}}$ as its inputs and produces two valid layouts $\pi^{O_{1}}$ and $\pi^{O_{2}}$ as its outputs. The description of this method is given in Algorithm 2. Let us now consider two valid layouts 


$$
\pi^{i_{1}}=\{6,5,2,9,7,10,4,3,1,8\}
$$

and

$$
\pi^{i_{2}}=\{9,10,1,3,4,8,5,2,6,7\} .
$$

In this example, the number of facilities $(n)$ is 10 . If we assume that line 1 of Algorithm 2 generates $r_{1}$ and $r_{2}$ as 3 and 6 , respectively, then lines 2 and 3 will create

$$
\pi^{O_{1}}=\{-,-, 1,3,4,8,-,-,-,-\}
$$

and

$$
\pi^{O_{2}}=\{-,-, 2,9,7,10,-,-,-,-\}
$$

respectively. The symbol ' - ' indicates that the facility at that position is yet to be determined. Thus, partial replacements of two layouts are done. In lines 4 and 5, the positions marked with ' - ' in $\pi^{O_{1}}$ and $\pi^{O_{2}}$ are filled with the facilities located at the same position in $\pi^{i_{1}}$ and $\pi^{i_{2}}$, respectively, if the corresponding facilities have not been included in earlier steps. They create $\pi^{O_{1}}=$ $\{6,5,1,3,4,8,-,-,-,-\}$ and $\pi^{O_{2}}=\{-,-, 2,9,7,10$, $5,2,-,-\}$. In the next step, the remaining positions marked with '- ' of both $\pi^{O_{1}}$ and $\pi^{O_{2}}$ are filled up with the remaining elements of $\pi^{i_{1}}$ and $\pi^{i_{2}}$, respectively, with the same order in which they appear in $\pi^{i_{1}}$ and $\pi^{i_{2}}$. These creates $\pi^{O_{1}}=\{6,5,1,3,4,8,2,9,7,10\}$ and $\pi^{O_{2}}=\{1,3$, $2,9,7,10,5,4,6,8\}$.

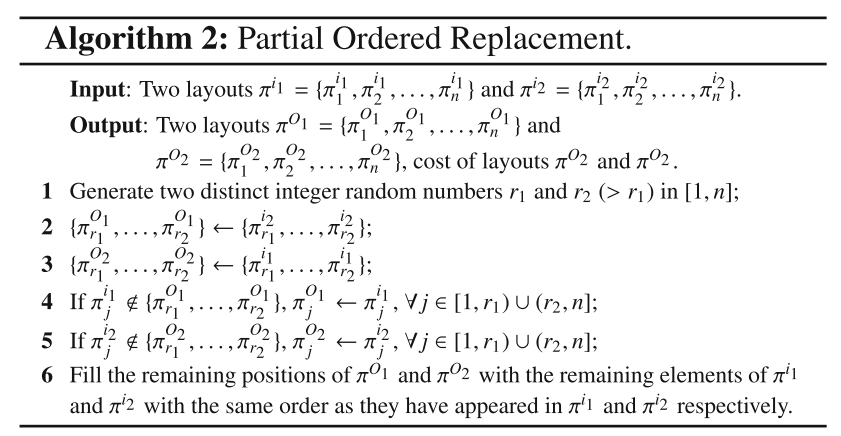

\subsection{Adjacent neighbour}

This local search method takes weight matrix $\mathcal{W}$, length matrix $\mathcal{L}$, an old set of layouts $\prod_{\text {old }}$ and neighbourhood size $(\alpha)$ as its inputs and generates a new set of layouts $\prod_{\text {new }}$ and its corresponding cost $\mathcal{C}_{\prod_{\text {new }}}$. Algorithm 3 gives a description of this local search method. We will show the mechanism of this method for only one layout $\pi^{i} \in \prod_{\text {old }}$ using an example. The computations for all the other layouts in $\prod_{\text {old }}$ will be similar. Let us consider $\mathcal{W}$ and $\mathcal{L}$ as shown in figure $2, \pi^{i}=\{3,2,4,1,5\}$ and $\alpha=2$. Since $\alpha$ is 2 , we consider $\pi_{1}^{i}, \pi_{2}^{i}$ at first, then compute all possible permutations of $\pi_{1}^{i}, \pi_{2}^{i}$, replace $\pi_{1}^{i}, \pi_{2}^{i}$ by each of the permutations and compare cost of $\pi^{i}$ with that of the modified $\pi^{i}$. We keep that modified $\pi^{i}$ for which cost is minimum. Then we again repeat the same procedure for $\pi_{2}^{i}, \pi_{3}^{i}$ up to $\pi_{4}^{i}, \pi_{5}^{i}$. Then we compare the cost of the current $\pi^{i}$ with that of the old $\pi^{i}$. If improvement occurs in terms of cost, then we change the old $\pi^{i}$ with the current one. For this example, at the end of this method we get $\pi^{o}$ as $\{2,3,1,5,4\}$. This method is so named because in each step we always consider the facilities within a predefined neighbourhood size, $\alpha$. The complexity of this method greatly depends on the value of $\alpha$. Hence, in our experiment, we will keep this value within the range $2-3$.

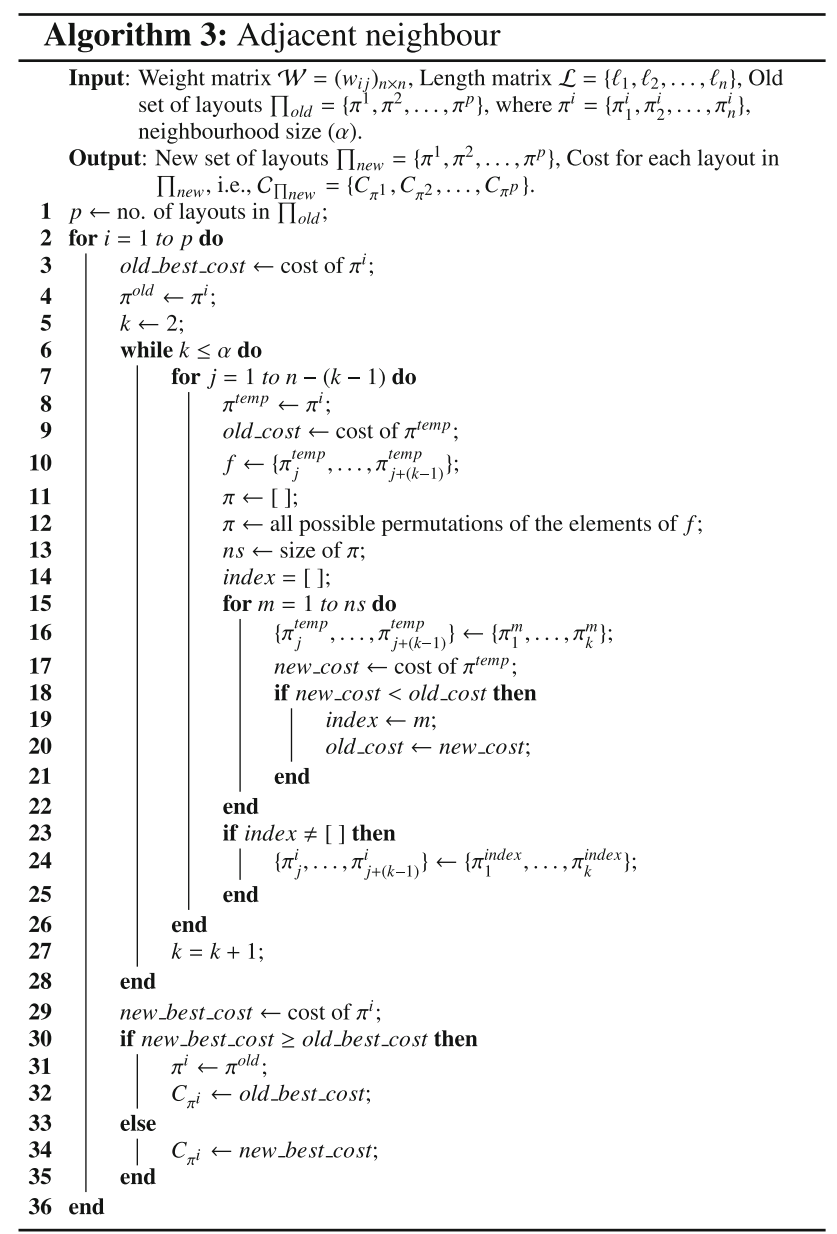

\subsection{Best permutation}

This improvement method takes weight matrix $\mathcal{W}$, length matrix $\mathcal{L}$ and a layout $\pi^{*}$ as its inputs and generates a new layout $\pi^{\circ}$ and its corresponding cost $\mathcal{C}_{\pi^{\circ}}$. The method is described in Algorithm 4. In this method, given a layout $\pi^{*}$, we will generate a few other permutations generated from $\pi^{*}$ and select that permutation for which the corresponding cost is minimum. This is the reason why we call this method as the best permutation, though we do not explore all the permutations of $\pi^{*}$ as this is time consuming if $n$ is large. Let us consider $\pi^{*}=\{1,2,3,4,5\}$. From this, we generate the permutations as shown in figure 4 . 

$2, \quad 1, \quad 3, \quad 4, \quad 5$
$2, \quad 3,1,4,5$
$2, \quad 3, \quad 4, \quad 1, \quad 5$
$1, \quad 3, \quad 2, \quad 4, \quad 5$
$2, \quad 3,4, \quad 5,1$
$1, \quad 3, \quad 4, \quad 2, \quad 5$
$1, \quad 3, \quad 4, \quad 5,2$
$\begin{array}{lllll}1, & 2, & 4, & 3, & 5 \\ 1, & 2, & 4, & 5, & 3\end{array}$
$1, \quad 2, \quad 3, \quad 5,4$

Figure 4. Generated permutations.

There is a relation between $\pi^{*}$ and $\pi^{\circ}$. Observe the first four permutations in the first column of figure 4 . In these four permutations, only the first element of $\pi^{*}$, i.e. 1 , is shifted to its right one place at a time. Then observe the permutations as shown in the second column of figure 4 , where the second element of $\pi^{*}$, i.e. 2 , is shifted to its right one place at a time and so on up to the second last element. The pattern of generating these permutations can be easily understood from figure 4 .

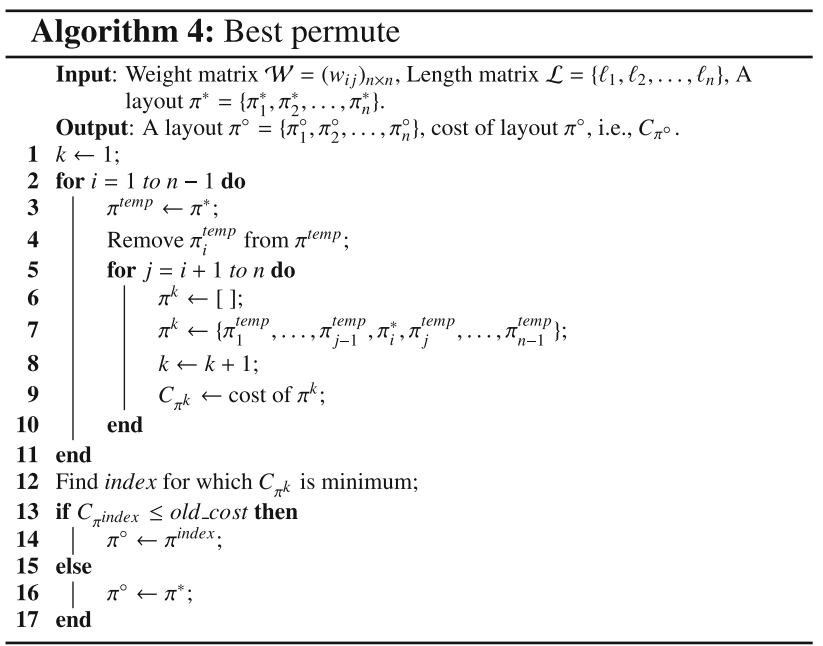

Note that this method of generating permutations from a given valid layout will explore $\frac{n(n-1)}{2}$ number of different permutations. Among all the generated permutations as shown in figure $4,\{2,3,4,5,1\}$ will be selected as $\pi^{\circ}$ because for this layout the corresponding cost is minimum and here the cost is 160 .

\subsection{Random replacement}

Random replacement is a heuristic method that is used to get diversity in the current population of solutions. This method helps in overcoming the difficulty of getting stuck into a local optimum. This method takes the weight matrix $\mathcal{W}$, the length matrix $\mathcal{L}$ and an old set of layouts $\prod_{\text {old }}$ and produces a new modified set of layout $\prod_{\text {new }}$ and the corresponding $\mathcal{C}_{\prod_{\text {new }}}$. This heuristic method is described in Algorithm 5. For a layout $\pi^{i} \in$ $\prod_{\text {old }}$, we generate two distinct numbers $r_{1}, r_{2} \in[1, n]$ and we swap $\pi_{r_{1}}^{i}$ and $\pi_{r_{2}}^{i}$ if improvement occurs in terms of cost. This step is repeated $n$ times for each layout.

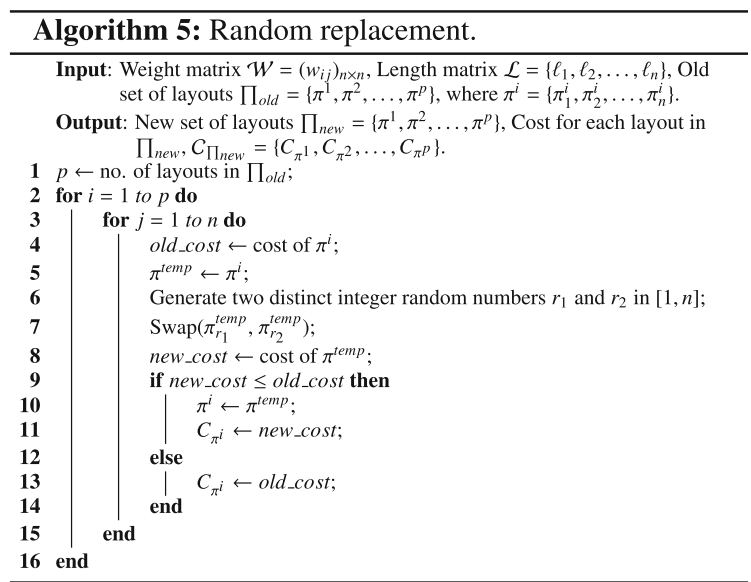

\subsection{Proposed heuristic algorithm for SRFLP}

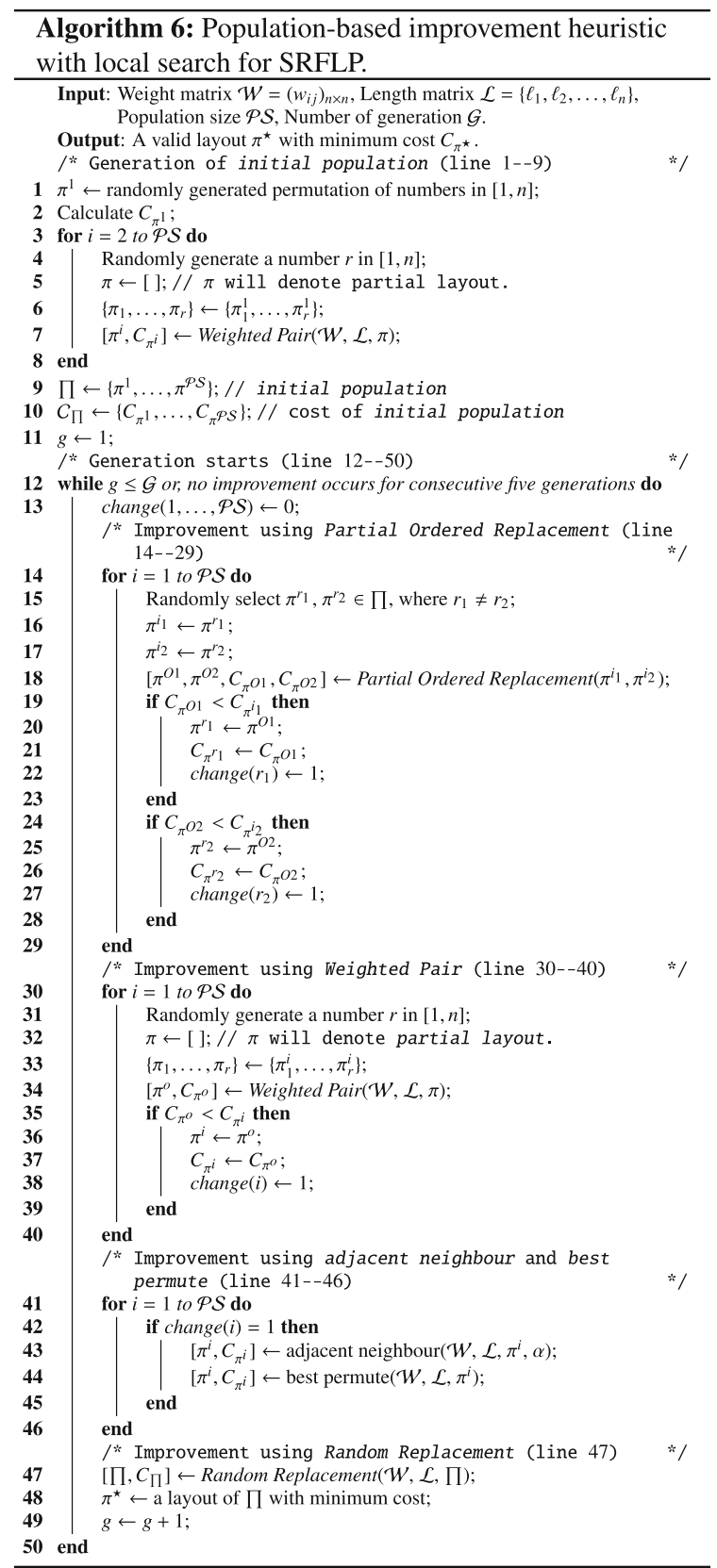


The population-based improvement heuristic algorithm with local search for SRFLP is proposed in this section. This algorithm takes the weight matrix $\mathcal{W}$, the length matrix $\mathcal{L}$, population size $\mathcal{P S}$, number of generation $\mathcal{G}$ and neighbourhood size $(\alpha)$ as its inputs and produces a valid layout $\pi^{\star}$ with minimum cost $C_{\pi^{\star}}$. The proposed heuristic algorithm for SRFLP is described in Algorithm 6. All the heuristic methods discussed previously are used for constructing this algorithm. Line 1 of Algorithm 6 generates a random solution and the cost of this solution is computed in line 2. The rest of the population is created by the Weighted Pair method using the random solution generated earlier. Generation starts in line 12 and it stops when either the maximum generation $\mathcal{G}$ is reached or no improvement occurs for any five consecutive generations in terms of cost of layout. A flag array change $[1, \ldots, \mathcal{P S}]$ is used to identify the layout that is modified in any particular generation. At the start of every generation, each element of change is initialized to 0 . Whenever an improvement of a solution occurs, then the corresponding element of change is set to 1. This flag array has an effect on the performance of the algorithm. Each solution in the population is improved using the Partial Ordered Replacement method first, followed by the Weighted Pair method. Note that these two

Table 1. Results for $\mathrm{N}$ type instances of SRFLP $(n=40)$.

\begin{tabular}{lccrlrr}
\hline & & & & \multicolumn{2}{c}{ Proposed heuristic } \\
\cline { 5 - 7 } Instance & $n$ & Cost $^{\mathrm{a}}$ & Time $^{\mathrm{a}}$ & & \multicolumn{1}{c}{ Cost } & Time \\
\hline N40_1 & 40 & 107348.5 & $01: 01: 36$ & 107348.5 & $\mathbf{0 0 : 0 0 : 3 7}$ \\
N40_2 & 40 & 97693 & $00: 52: 52$ & 97693 & $\mathbf{0 0 : 0 0 : 3 9}$ \\
N40_3 & 40 & 78589.5 & $01: 21: 40$ & 78589.5 & $\mathbf{0 0 : 0 0 : 4 2}$ \\
N40_4 & 40 & 76669 & $01: 15: 58$ & 76669 & $\mathbf{0 0 : 0 0 : 3 5}$ \\
N40_5 & 40 & 103009 & $02: 20: 09$ & 103009 & $\mathbf{0 0 : 0 0 : 3 8}$ \\
\hline
\end{tabular}

${ }^{a}$ Refers to the results reported in [22]

'Time' indicates the computational time in min:s or in h:min:s

Table 2. Best layouts obtained for $\mathrm{N}$ type instances of SRFLP.

\begin{tabular}{|c|c|}
\hline Instance & Best layout \\
\hline N40_1 & $\begin{array}{l}341220102719928173758211535243823640 \\
18337112532222663033129423141391613\end{array}$ \\
\hline N40_2 & $\begin{array}{l}14815363126401433352511271693228195 \\
391320342122229101817233036127383724\end{array}$ \\
\hline N40_3 & $\begin{array}{l}1411173913425129115312829183852103 \\
33626371620823403632342130272422735 \\
19\end{array}$ \\
\hline N40_4 & $\begin{array}{l}291917113820283781423725353923991526 \\
323133301634536272212113102440181246\end{array}$ \\
\hline N40_5 & $\begin{array}{l}12212923922453227136332620619142818 \\
393830373510434151316402573122811317\end{array}$ \\
\hline
\end{tabular}

methods modify a solution only if improvement occurs in terms of cost. Otherwise, the old solution is kept unchanged. If improvement occurs, then the corresponding

Table 3. Results for $\mathrm{O}, \mathrm{S}, \mathrm{Y}$ and $\mathrm{N}$ types of SREFLP instances $(5 \leq n \leq 35)$.

\begin{tabular}{|c|c|c|c|c|c|c|}
\hline \multirow[b]{2}{*}{ Instance } & \multirow[b]{2}{*}{$n$} & \multirow[b]{2}{*}{$\operatorname{Cost}^{\mathrm{a}}$} & \multirow[b]{2}{*}{ Time $^{\mathrm{b}}$} & \multirow[b]{2}{*}{ Time $^{c}$} & \multicolumn{2}{|c|}{ Proposed heuristic } \\
\hline & & & & & Cost & Time \\
\hline $\mathrm{O}-5$ & 5 & 150 & 1 & 1 & 150 & 0.03 \\
\hline O-6 & 6 & 292 & 1 & 1 & 292 & 0.04 \\
\hline O-7 & 7 & 472 & 1 & 1 & 472 & 0.05 \\
\hline O-8 & 8 & 784 & 1 & 1 & 784 & 0.09 \\
\hline O-9 & 9 & 1032 & 1 & 1 & 1032 & 0.12 \\
\hline O-10 & 10 & 1402 & 1 & 1 & 1402 & 0.18 \\
\hline O-15 & 15 & 5134 & 2 & 4 & 5134 & 0.44 \\
\hline O-20 & 20 & 12924 & 37 & 37 & 12924 & 0.73 \\
\hline S-12 & 12 & 4431 & 1 & 4 & 4431 & 0.24 \\
\hline S-13 & 12 & 5897 & 1 & 4 & 5897 & 0.40 \\
\hline S-14 & 14 & 7316 & 1 & 15 & 7316 & 0.89 \\
\hline S-15 & 15 & 8942 & 2 & 19 & 8942 & 1.02 \\
\hline$S-16$ & 16 & 11019 & 3 & 27 & 11019 & 1.21 \\
\hline S-17 & 17 & 13172 & 5 & 50 & 13172 & 1.26 \\
\hline S-18 & 18 & 15699 & 8 & 48 & 15699 & 1.66 \\
\hline S-19 & 19 & 18700 & 22 & 01:43:00 & 18700 & 2.15 \\
\hline S-20 & 20 & 21825 & 55 & 02:09:00 & 21825 & 2.07 \\
\hline$S-21$ & 21 & 24891 & 01:41:00 & 03:20:00 & 24891 & 7.01 \\
\hline$S-22$ & 22 & 28607 & 03:48:00 & 03:57:00 & 28607 & 8.10 \\
\hline$S-23$ & 23 & 33046 & $08: 12: 00$ & 03:15:00 & 33046 & 9.86 \\
\hline S-24 & 24 & 37498 & $13: 41: 00$ & 03:31:00 & 37498 & 11.13 \\
\hline S-25 & 25 & 42349 & $36: 21: 00$ & 07:07:00 & 42349 & 11.29 \\
\hline Y-6 & 6 & 1372 & 1 & 1 & 1372 & 0.04 \\
\hline$Y-7$ & 7 & 1801 & 1 & 1 & 1801 & 0.07 \\
\hline Y-8 & 8 & 2302 & 1 & 1 & 2302 & 0.09 \\
\hline Y-9 & 9 & 2808 & 1 & 1 & 2808 & 0.13 \\
\hline$Y-10$ & 10 & 3508 & 1 & 2 & 3508 & 0.20 \\
\hline Y-11 & 11 & 4022 & 1 & 4 & 4022 & 0.51 \\
\hline$Y-12$ & 12 & 4793 & 1 & 10 & 4793 & 0.58 \\
\hline Y-13 & 13 & 5471 & 1 & 9 & 5471 & 0.63 \\
\hline Y-14 & 14 & 6445 & 1 & 34 & 6445 & 0.87 \\
\hline$Y-15$ & 15 & 7359 & 2 & 26 & 7359 & 1.04 \\
\hline$Y-20$ & 20 & 12185 & 23 & 01:14:00 & 12185 & 3.09 \\
\hline$Y-25$ & 25 & 20357 & $22: 38: 00$ & $05: 14: 00$ & 20357 & 5.27 \\
\hline$Y-30$ & 30 & 27673 & $16: 17: 07$ & $17: 46: 00$ & 27673 & 18.03 \\
\hline$Y-35$ & 35 & 38194 & 459:08:51 & $25: 50: 00$ & 38194 & 27.23 \\
\hline N-15 & 15 & 2186 & 2 & 17 & 2186 & 0.90 \\
\hline $\mathrm{N}-16 \mathrm{a}$ & 16 & 3050 & - & 8 & 3050 & 0.98 \\
\hline $\mathrm{N}-16 \mathrm{~b}$ & 16 & 2400 & - & 6 & 2400 & 1.01 \\
\hline $\mathrm{N}-17$ & 17 & 3388 & - & 13 & 3388 & 1.03 \\
\hline $\mathrm{N}-18$ & 18 & 3986 & - & 16 & 3986 & 1.17 \\
\hline $\mathrm{N}-20$ & 20 & 5642 & 41 & 01:11:00 & 5642 & 4.07 \\
\hline $\mathrm{N}-21$ & 21 & 5084 & - & $01: 16: 00$ & 5084 & 4.84 \\
\hline $\mathrm{N}-22$ & 22 & 6184 & - & 01:20:00 & 6184 & 4.59 \\
\hline $\mathrm{N}-24$ & 24 & 8270 & - & $02: 12: 00$ & 8270 & 5.19 \\
\hline
\end{tabular}

${ }^{\text {a }}$ Refers to the results reported in [14]

${ }^{\mathrm{b}}$ Refers to the results reported in [23]

${ }^{\mathrm{c}}$ Refers to the results reported in [22]

'Time' indicates the computational time in s, min:s or h:min:s 


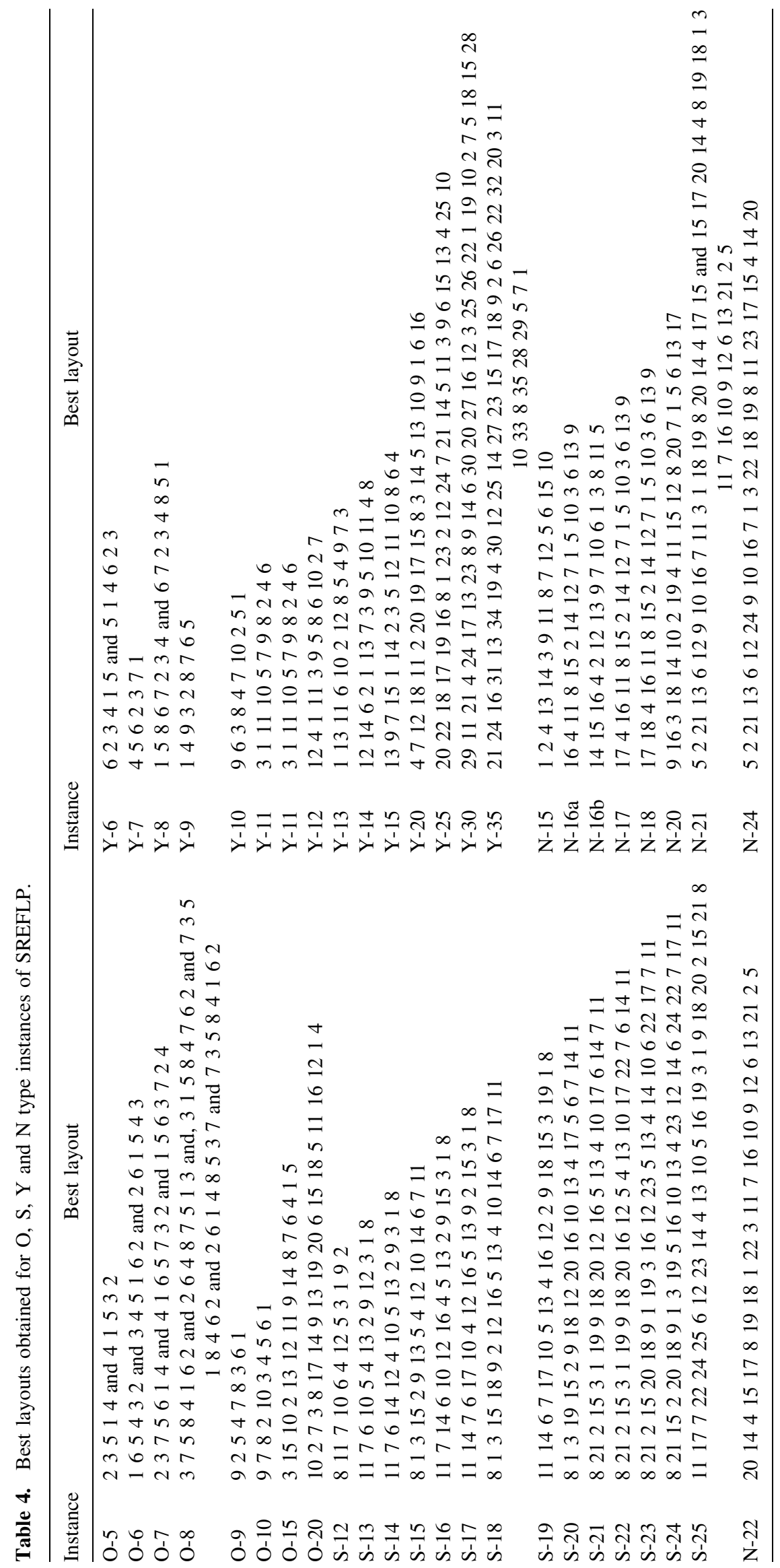


Table 5. Performance comparison for Anjos instances $(60 \leq n \leq 80)$.

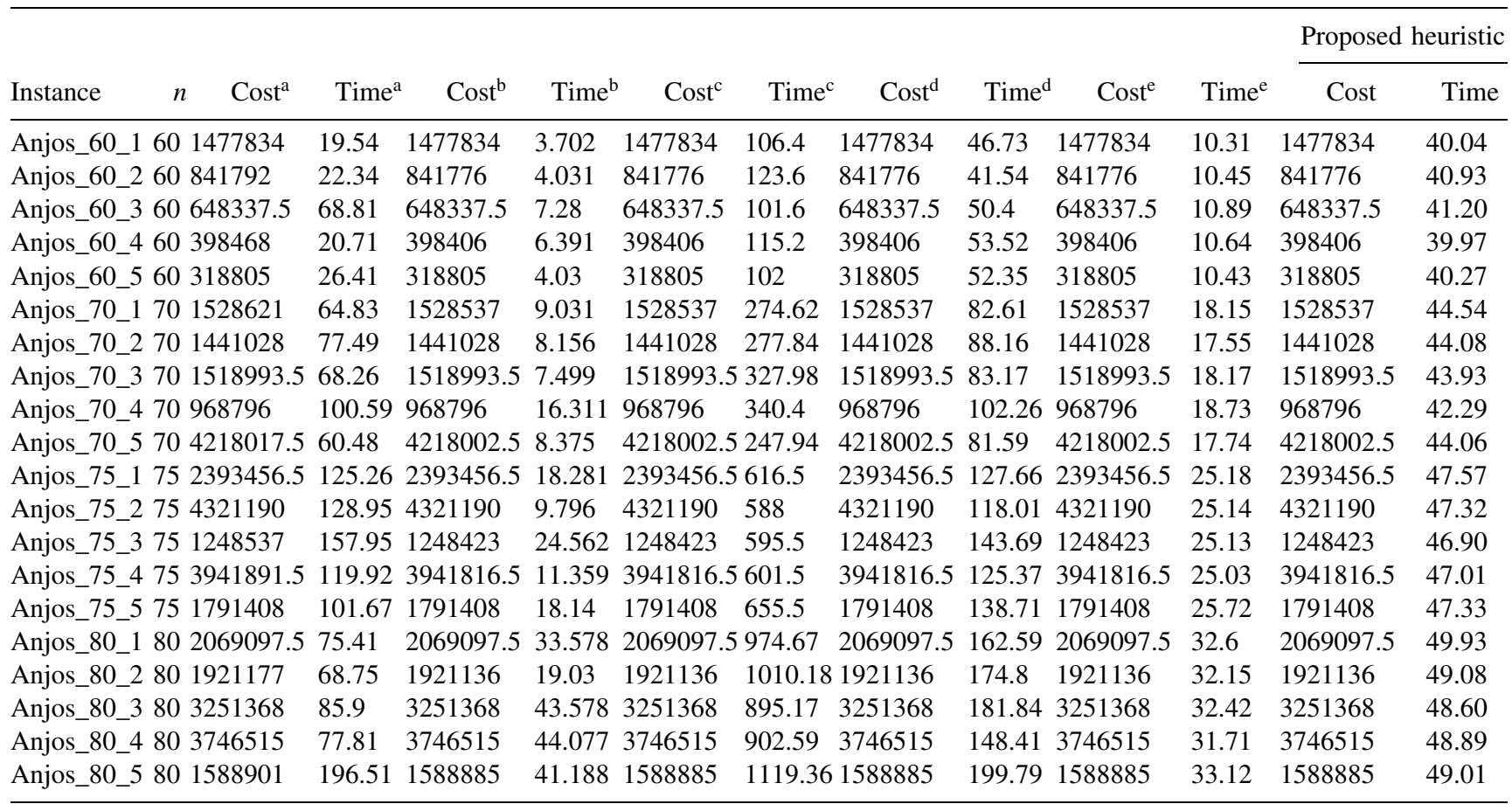

${ }^{a}$ Refers to the results reported in [8]

${ }^{\mathrm{b}}$ Refers to the results reported in [24]

${ }^{\mathrm{c}}$ Refers to the results reported in [10]

${ }^{\mathrm{d}}$ Refers to the results reported in [25]

${ }^{\mathrm{e}}$ Refers to the results reported in [13]

'Time' indicates the computational time in seconds

element of change is set to 1 . Now two local search methods, viz. adjacent neighbour and best permutation, are used to improve a solution only if the corresponding element of change is 1 . This strategy is useful to minimize the computation time of the algorithm. We employ this strategy because for the same input layout, these two local search improvement methods create the same output layout. The Random Replacement method is used at the end to introduce diversity in the solutions if any solution gets stuck to local optima. Again, the next generation is started with the modified population of layouts if termination condition is not met.

\section{Results and discussion}

The effectiveness of the proposed heuristic algorithm is tested with the instances of sizes ranging from 5 to 300 . Note that the size of an instance is defined by the number of facilities. In this article, the instances of SRFLP and SREFLP are taken from FLPLIB: Facility Layout Database (http://www.miguelanjos.com/flplib) and [54]. The proposed heuristic algorithm is programmed using
MATLAB and run on an Intel Core i5 with $3.10 \mathrm{GHz}$ processor and 8 GB RAM having Ubuntu 16.04 LTS operating system. In the experiment, when the instance size is less than 10 , between 10 and 50 , and more than 50 , the population size $(\mathcal{P S})$ is considered as 4,12 and 24 , respectively. The neighbourhood size $(\alpha)$ is considered as 2 when the instance size is less than or equal to 50 and it is considered as 3 when the instance size is more than 50 . We have set these parameter values experimentally. In this article, the results reported are the best results obtained by running the proposed algorithm 10 times on each problem instance.

For comparatively smaller instances of sizes up to 40 facilities, we have compared the performance of the proposed algorithm with different exact algorithms based on mathematical programming $[14,22,23]$. For larger instances of sizes up to 300 facilities, we have used different meta-heuristic algorithms $[8,10,13,24-26]$ for comparison.

The $\mathrm{N}$ type instances [22] of SRFLP with 40 facilities are first considered in this article. The result obtained for each of the instances using the proposed algorithm is shown in table 1 and the corresponding best layout is mentioned in 
Table 6. Best layouts obtained for Anjos type instances of SRFLP.

\begin{tabular}{|c|c|}
\hline Instance & Best layout \\
\hline Anjos_60_1 & $\begin{array}{l}1341839205560583019595210535037433145235382941492242141722683332435131644369 \\
47125775446516254032115242856481127\end{array}$ \\
\hline Anjos_60_2* & $\begin{array}{l}53101341295030915428143432403328215637255241543917464518365227643595126555816 \\
6038477493131248232419225735441120\end{array}$ \\
\hline Anjos_60_3* & $\begin{array}{l}51934238291624482011414421214525537571218159354033508434630263917604525562823 \\
5851710313432113542227473649535964\end{array}$ \\
\hline Anjos_60_4 & $\begin{array}{l}1320311955571039744242236335611216231746405953534525035142715185881660292642 \\
37544730513248529493828144134254312\end{array}$ \\
\hline Anjos_60_5 & $\begin{array}{l}39533771647594194154913255461735203036604028825486501027214256244531581551518 \\
2223571432294326111338345244493312\end{array}$ \\
\hline Anjos_70_1 & $\begin{array}{l}5347654022862221583296331695168141664614138566770441026141933424953036235560 \\
13182124275411125865952720663344546254348172957 \quad 3935 \quad 3750\end{array}$ \\
\hline Anjos_70_2 & $\begin{array}{l}2839505352104721362617319136958967332345296218306311146864944432442168402420 \\
5446225271537343132553512651738607066484159516164572556\end{array}$ \\
\hline Anjos_70_3 & $\begin{array}{l}8306351542729432132232420141676479261165224617701924237685010144953518562528 \\
6639364033562604513554812595838334615646934173157524416\end{array}$ \\
\hline Anjos_70_4 & $\begin{array}{l}1625715305147529635466422112961423312142358606853242654623418365012844273749 \\
5657695919701721675562402048433133210456531393848356641\end{array}$ \\
\hline Anjos_70_5 & $\begin{array}{l}19389168236231512405837502239106541665632749826614143562414352070530361242153 \\
117293460463664259155545485725475213183369326444172867\end{array}$ \\
\hline Anjos_75_1 & $\begin{array}{l}3847461629963725428515133321845172225117539625343368704166103134121974204232 \\
24237405571444173566550233049156156182659275236577367694860146458\end{array}$ \\
\hline Anjos_75_2* & $\begin{array}{l}25264356377247706630394535246954331041419319741748364655136816382715628122322 \\
1167343716575205355258732915759718506042406314644282216132645149\end{array}$ \\
\hline Anjos_75_3 & $\begin{array}{l}2250541146353552587218706638237443031621633459524963274073587592435282145675 \\
576511714813271236205661647439460266823294641514317 \quad 15331910426947\end{array}$ \\
\hline Anjos_75_4* & $\begin{array}{l}21179497238696827256516174113147143545958232666635648551926713213452418347344 \\
5328521665356431246393340294120572247307083762421075750151456036\end{array}$ \\
\hline Anjos_75_5* & $\begin{array}{l}24203772525150603543581687144477432765736623312238498423281710530701255292546 \\
4534365911575448156745621697539611841 \quad 16531440 \quad 6462 \quad 2661319639263327\end{array}$ \\
\hline Anjos_80_1* & $\begin{array}{l}55702608067442765402116294319461463613953521268474575495134625666544841322010 \\
50581542769313662223743313172437187692672733055935387738642814717911572578\end{array}$ \\
\hline Anjos_80_2* & $\begin{array}{l}1166614548434963695180607864523171377977030737659196826137542624450265834409 \\
363938420533676213525232827721773316294154124774325615461458555171024185722\end{array}$ \\
\hline Anjos_80_3* & $\begin{array}{l}57635453376261262932643548723022257667771050525183397827178044211411592374119 \\
73751511827155606693831612287965564422454547464313706949343668203316584074\end{array}$ \\
\hline Anjos_80_4 & $\begin{array}{l}6960647571383578543046283242668012437476142996227176418671537162207231197952 \\
261334837537713498516570559113945682325736334245510443621585722566140504147\end{array}$ \\
\hline Anjos_80_5* & $\begin{array}{l}25174841586069781349427212291651146426282415565575046236340452080418773932359 \\
65556671355343644547579343062363376919318701221174371068672173612738524772\end{array}$ \\
\hline
\end{tabular}

*Indicates that the best layout is same as mentioned in [54]

table 2. The proposed algorithm finds the optimal cost for each of the instances. It is evident from table 1 that the proposed algorithm significantly improves the computational time.

The O [55], S [56], Y [17] and N [57] type instances of SREFLP are considered with up to 35 facilities in table 3. All the facilities have the same length for these instances. Columns 4 and 5 of table 3 give the computational times required using specialized LP-based branch and bound approach [23] and general SDP-based approach [22], respectively. It is clear from table 3 that the optimal cost as mentioned in [14] is achieved for each instance using the proposed algorithm and the computational time is improved significantly. The corresponding best layout for each of the $\mathrm{O}, \mathrm{N}, \mathrm{S}$ and $\mathrm{Y}$ type instances is given in table 4 . Note that there exists more than one layout for $\mathrm{O}-6, \mathrm{O}-7, \mathrm{O}-8$ and $\mathrm{N}-21$ instances with the same cost. It is also to be noted that the reverse of a particular layout gives the same cost and in this article, we have considered a layout and its reverse as the same solution.

The Anjos benchmark instances [38] are considered next in this article. This benchmark data set consists of 20 instances of sizes ranging from 60 to 80 . We have 
Table 7. Performance comparison for sko instances $(64 \leq n \leq 100)$.

\begin{tabular}{|c|c|c|c|c|c|c|c|c|c|c|c|}
\hline \multirow[b]{2}{*}{ Instance } & \multirow[b]{2}{*}{$n$} & \multirow[b]{2}{*}{$\operatorname{Cost}^{\mathrm{b}}$} & \multirow[b]{2}{*}{ Time $^{\mathrm{b}}$} & \multirow[b]{2}{*}{$\operatorname{Cost}^{\mathrm{c}}$} & \multirow[b]{2}{*}{ Time $^{c}$} & \multirow[b]{2}{*}{$\operatorname{Cost}^{\mathrm{d}}$} & \multirow[b]{2}{*}{ Time $^{\mathrm{d}}$} & \multirow[b]{2}{*}{$\operatorname{Cost}^{\mathrm{e}}$} & \multirow[b]{2}{*}{ Time $^{\mathrm{e}}$} & \multicolumn{2}{|c|}{ Proposed heuristic } \\
\hline & & & & & & & & & & Cost & Time \\
\hline sko-64-01 & 64 & - & - & 96933 & 196.98 & 96883 & 82.8 & 96881 & 15.37 & 96881 & 41.23 \\
\hline sko-64-02 & 64 & - & - & 634338.5 & 189.84 & 634332.5 & 68.31 & 634332.5 & 13.98 & 634332.5 & 40.97 \\
\hline sko-64-03 & 64 & - & - & 414323.5 & 185.22 & 414323.5 & 80.33 & 414323.5 & 14.12 & 414323.5 & 41.56 \\
\hline sko-64-04 & 64 & - & - & 297205 & 190.68 & 297129 & 91.05 & 297129 & 14.28 & 297129 & 39.97 \\
\hline sko-64-05 & 64 & - & - & 501922.5 & 182.7 & 501922.5 & 75.86 & 501922.5 & 13.92 & 501922.5 & 41.26 \\
\hline sko-72-01 & 72 & - & - & 139150 & 465.12 & 139150 & 115.21 & 139150 & 25.55 & 139150 & 45.57 \\
\hline sko-72-02 & 72 & - & - & 712005 & 419.04 & 711998 & 192.12 & 711998 & 22.99 & 711998 & 45.02 \\
\hline sko-72-03 & 72 & - & - & 1054110.5 & 412.8 & 1054110.5 & 114.16 & 1054110.5 & 22.48 & 1054110.5 & 45.97 \\
\hline sko-72-04 & 72 & - & - & 919635.5 & 418.56 & 919586.5 & 135.46 & 919586.5 & 22.3 & 919586.5 & 44.92 \\
\hline sko-72-05 & 72 & - & - & 428879.5 & 433.44 & 428226.5 & 116.5 & 428226.5 & 23.28 & 428226.5 & 44.98 \\
\hline sko-81-01 & 81 & - & - & 205166 & 1298.16 & 205106 & 311.63 & 205108.5 & 40.74 & 205106 & 48.01 \\
\hline sko-81-02 & 81 & - & - & 521391.5 & 1402.38 & 521391.5 & 226.91 & 521391.5 & 36.33 & 521391.5 & 47.89 \\
\hline sko-81-03 & 81 & - & - & 970862 & 1276.56 & 970796 & 241.5 & 970796 & 35.88 & 970796 & 47.56 \\
\hline sko-81-04 & 81 & - & - & 2031979 & 1425.06 & 2031803 & 193.98 & 2031803 & 37.49 & 2031803 & 48.07 \\
\hline sko-81-05 & 81 & - & - & 1303805 & 1301.4 & 1302711 & 287.22 & 1302711 & 35.94 & 1302711 & 48.11 \\
\hline sko-100-01 & 100 & 378234 & 1220.76 & 378614 & 7279.14 & 378234 & 877.12 & 378234 & 99.34 & 378234 & 57.93 \\
\hline sko-100-02 & 100 & 2076008.5 & 91.98 & 2076048.5 & 7632.9 & 2076008.5 & 526.09 & 2076008.5 & 86.1 & 2076008.5 & 57.27 \\
\hline sko-100-03 & 100 & 16145614.5 & 505.92 & 16148818 & 7510.8 & 16145614 & 599.92 & 16145598 & 82.37 & 16145614.5 & 57.89 \\
\hline sko-100-04 & 100 & 3232522 & 405 & 3232740 & 7395.96 & 3232531 & 592 & 3232522 & 80.61 & 3232522 & 58.92 \\
\hline sko-100-05 & 100 & 1033080.5 & 518.28 & 1033345.5 & 7087.08 & 1033080.5 & 591.75 & 1033080.5 & 84.63 & 1033080.5 & 57.98 \\
\hline
\end{tabular}

${ }^{\mathrm{b}}$ Refers to the results reported in [24]

${ }^{\mathrm{c}}$ Refers to the results reported in [10]

${ }^{\mathrm{d}}$ Refers to the results reported in [25]

${ }^{\mathrm{e}}$ Refers to the results reported in [13]

'Time' indicates the computational time in seconds

Missing entry ('-') indicates that the corresponding method has not been applied to the instance

compared the performance of the proposed algorithm for these 20 large size instances to those of the recently developed five meta-heuristic algorithms, and the performance comparison is given in table 5. The first column of table 5 gives the name of the instance. The second column gives the number of facilities $(n)$. The performance of the proposed algorithm has been compared to that of a permutation-based genetic algorithm (GA) [8], a hybrid GA with local search [24], insertion-based Lin-Kernighan heuristic proposed in [10], scatter search algorithm [25] and a GA incorporated with local search [13]. The proposed algorithm achieves the best known cost for every instance as compared with the literature, and the computation time is comparable to those of other existing methods. The best layouts found by the proposed algorithm are given in table 6 .

Next, we considered sko [58] benchmark instances, which were originally used for Quadratic Assignment Problem (QAP) [59] and later these instances were adapted for SRFLP in [7]. Here, 20 large size sko instances have been used. The size of these instances ranges from 64 to 100. The performance comparisons of the proposed algorithm for these 20 instances to the four heuristic methods are given in table 7 . Here, we have compared the performance of the proposed algorithm to those of two customized genetic algorithms [13, 24], insertion-based LinKernighan heuristic [10] and scatter search algorithm [25]. The layouts corresponding to the best cost mentioned in table 7 are given in table 8 . The computational time requirements of the proposed algorithm and the methods proposed by Kothari and Ghosh [10, 13, 25] are graphically compared in figures 5 and 6.

We have also considered Amaral instances, each having 110 facilities [60]. The performance of the proposed algorithm is tested with two customized GAs [13, 24], insertionbased Lin-Kernighan heuristic [10] and scatter search algorithm [25]. The performance comparison for these three Amaral instances is given in table 9 and the corresponding best layouts are given in table 10. The computational time required by the proposed algorithm for each of the Amaral instances is graphically compared in figure 7 with the time required by each of the methods of Ozcelik [24] and Kothari and Ghosh [10, 13, 25].

We further investigate the performance of the proposed algorithm with larger instances of SRFLP. These benchmark instances having size ranging from 110 to 300 are 
Table 8. Best layouts obtained for sko type instances of SRFLP.

\begin{tabular}{|c|c|}
\hline Instance & Best layout \\
\hline sko-64-01 & $\begin{array}{l}15361227614134346325411284330540395147638485562201964442531610491323522992224 \\
588142144334517592617375025562636018355731\end{array}$ \\
\hline sko-64-02* & $\begin{array}{l}855319254264626357222658109313313244244594921173556165037174529232060485528638 \\
155261364614111239413454433514053027321847\end{array}$ \\
\hline sko-64-03 & $\begin{array}{l}66259507204832193733825411402826605391453438173530471843632510532457581444331 \\
272155645136461623225242913494241569611215\end{array}$ \\
\hline sko-64-04 & $\begin{array}{l}155957531154324130819103356251723850263437174547354458134921244643962516231229 \\
55229284814406152186351462063274336426031\end{array}$ \\
\hline sko-64-05 & $\begin{array}{l}625915255350261719244137577832383433391154414535215630244860284023327431475143 \\
56164255581364101452126146204963292218936\end{array}$ \\
\hline sko-72-01 & $\begin{array}{l}125331646018358561070273017672121422282647655223612917385946493350133763323916 \\
967144555736516842404841 \quad 151958206643462726925511455424343\end{array}$ \\
\hline sko-72-02 & $\begin{array}{l}345584145116264209407117119466654167261153669685726445524673933292548425185031 \\
214973027238466022352810705247655334363373213592314561812\end{array}$ \\
\hline sko-72-03* & $\begin{array}{l}58772155324938514155207134143629445740451132661968244252692512374365347351627 \\
5433482364226563134650821626159701030262896717391860561431\end{array}$ \\
\hline sko-72-04* & $\begin{array}{l}12356642472455036412011656115466436263375834692565318519399686716544851424044 \\
5755312938604623492214353371701310307272814752262123259178\end{array}$ \\
\hline sko-72-05 & $\begin{array}{l}512934407194423173338551641585946656191520144966686136457455692511242613433247 \\
524262632250372112235721731676460394830285427701018563538\end{array}$ \\
\hline sko-81-01 & $\begin{array}{c}847605453167634401028466429727177807579126337512459437318205827516213683252452 \\
447857115522423570263639731493819151481214164172369336567564895025306136674\end{array}$ \\
\hline sko-81-02* & $\begin{array}{r}828776064577616477254627632710392018244353757140597337681346517815857929803212 \\
452441931263491144265303667235041707466331769321611565648521481352549385522\end{array}$ \\
\hline sko-81-03* & $\begin{array}{l}47775316445410344076605963203751131864685721276224784374922455258697573187132 \\
4656467422317506541668126368019123338703256121415319564872281155297974393530\end{array}$ \\
\hline sko-81-04 & $\begin{array}{l}667482526656923513148120502306121122864491119171570483346397240343249604673756 \\
784254101835365514552276258756447637331136857767724533816435974152922797180\end{array}$ \\
\hline sko-81-05 & 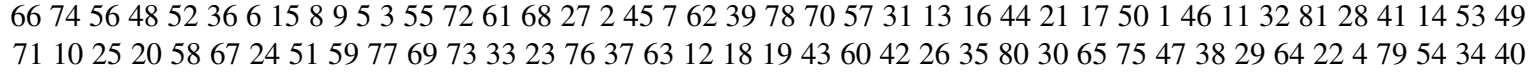 \\
\hline sko-100-01 & $\begin{array}{l}335442917217765345123650414861234927082923872816490664751462610069204014994394 \\
6785733024898689396456984219599848786625222163134758054551327106028573263588 \\
77255874951161533793983377191197781865\end{array}$ \\
\hline sko-100-02 & $\begin{array}{l}789197582753924426510731893882532119560649853096625463718313758479223487743757 \\
6801689152831555642382119864490664798221525149924567354620697010059144381868 \\
40267723894504876364177611253399172933\end{array}$ \\
\hline sko-100-03* & $\begin{array}{l}44789735398924805421537718291316327138375111614962657330859996129356951045574 \\
25118847957632772088348122151742982659236446752516750942948363872198687686690 \\
24369704147100614092534945766033828583\end{array}$ \\
\hline sko-100-04 & $\begin{array}{l}494239797125329397185945268898839168822334321277580246067862831741989541515696 \\
654918555131178635762377759816150924890100384626826953357266703651104020304773 \\
144187346495442923121799276584584637\end{array}$ \\
\hline sko-100-05* & $\begin{array}{l}789055632513586308460465967428855475108024273115953771971183394289169911857795 \\
88224333771329356813473648714220679946412653946840368266497044810035217479829 \\
61595169196223121738925272864548503768\end{array}$ \\
\hline
\end{tabular}

*Indicates that the best layout is the same as mentioned in [54] 


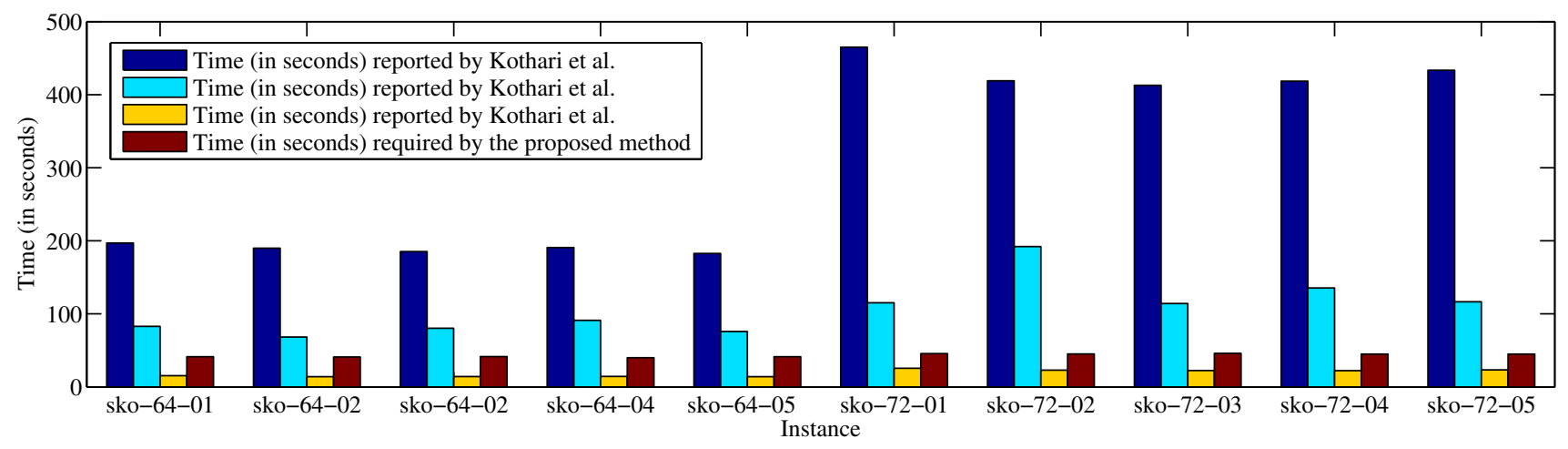

Figure 5. Performance comparison with Kothari and Ghosh $[10,13,25]$ for sko SRFLP instances $(n=64,72)$ (see the first 10 rows of table 7).

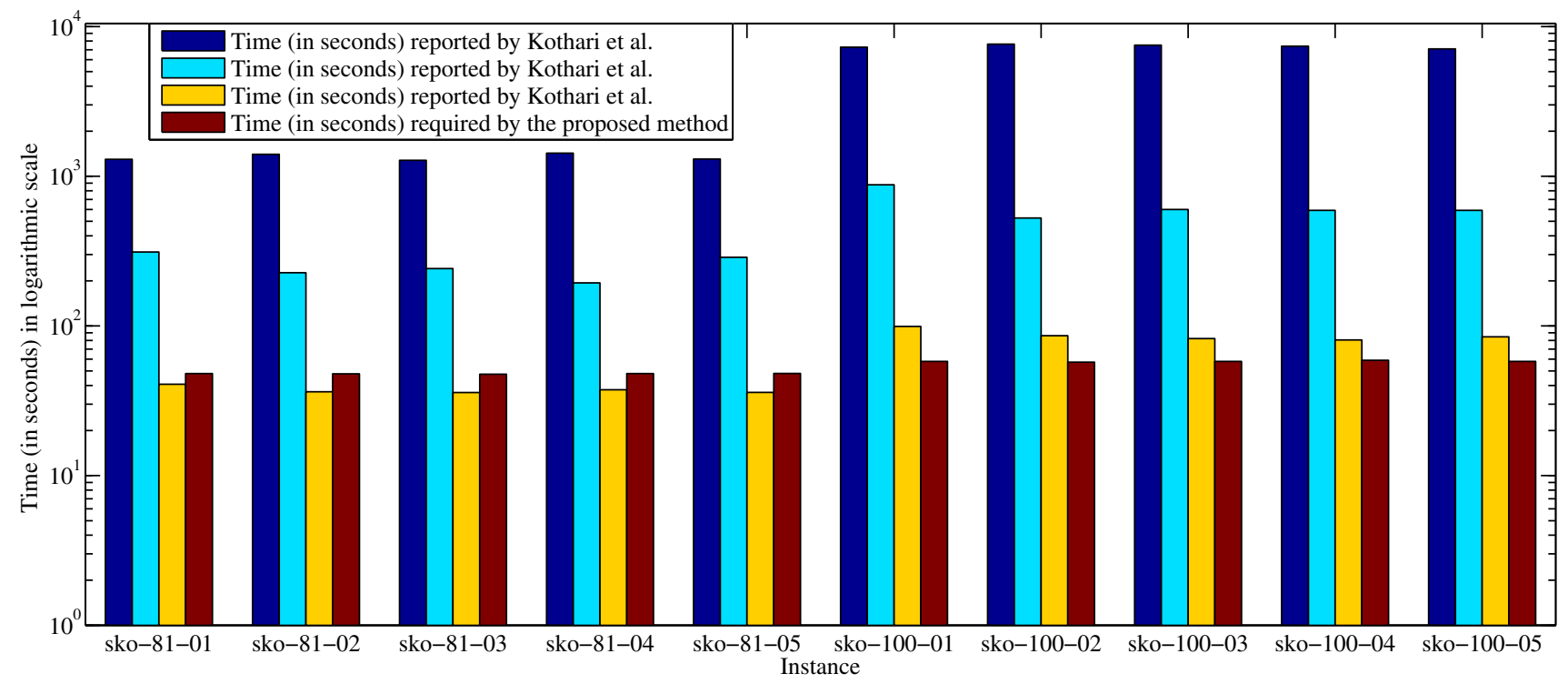

Figure 6. Performance comparison with Kothari and Ghosh $[10,13,25]$ for sko SRFLP instances $(n=81,100)$ (see the last 10 rows of table 7).

Table 9. Performance comparison for Amaral instances $(n=110)$.

\begin{tabular}{|c|c|c|c|c|c|c|c|c|c|c|c|}
\hline \multirow[b]{2}{*}{ Instance } & \multirow[b]{2}{*}{$n$} & \multirow[b]{2}{*}{$\operatorname{Cost}^{\mathrm{b}}$} & \multirow[b]{2}{*}{ Time $^{b}$} & \multirow[b]{2}{*}{$\operatorname{Cost}^{\mathrm{c}}$} & \multirow[b]{2}{*}{ Time $^{c}$} & \multirow[b]{2}{*}{$\operatorname{Cost}^{\mathrm{d}}$} & \multirow[b]{2}{*}{ Time $^{\mathrm{d}}$} & \multirow[b]{2}{*}{$\operatorname{Cost}^{\mathrm{e}}$} & \multirow[b]{2}{*}{ Time $^{\mathrm{e}}$} & \multicolumn{2}{|c|}{ Proposed heuristic } \\
\hline & & & & & & & & & & Cost & Time \\
\hline Amaral-110-01 & 110 & 144296664.5 & 574.08 & 144330992 & 10514.19 & 144297440 & 975.11 & 144296768 & 119.02 & 144296664.5 & 88.91 \\
\hline Amaral-110-02 & 110 & 86050037 & 553.68 & 86060416 & 12810.04 & 86050208 & 680.1 & 86050112 & 189.56 & 86050037 & 89.46 \\
\hline Amaral-110-03 & 110 & 2234743.5 & 744.66 & 2234825.5 & 10052.1 & 2234798.5 & 811.08 & 2234743.5 & 119.02 & 2234743.5 & 92.37 \\
\hline
\end{tabular}

\footnotetext{
${ }^{b}$ Refers to the results reported in [24]

${ }^{c}$ Refers to the results reported in [10]

${ }^{d}$ Refers to the results reported in [25]

${ }^{e}$ Refers to the results reported in [13]
}

'Time' indicates the computational time in seconds 
Table 10. Best layouts obtained for Amaral type instances of SRFLP.

\begin{tabular}{|c|c|}
\hline Instance & Best layout \\
\hline Amaral-110-01* & 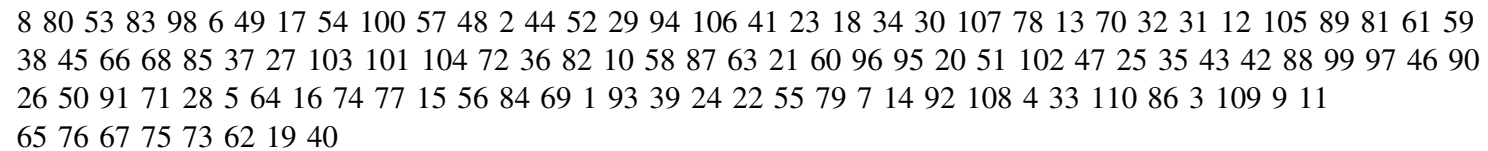 \\
\hline Amaral-110-02* & $\begin{array}{l}6462113331110469742554165578696475534801458370101917548519469956261588 \\
397677 \\
841072307379328224235921082310071684908594526727883826024491097171931635343 \\
66453861294120278944105958179110503610659109102983765103182167873240128\end{array}$ \\
\hline Amaral-110-03 & $\begin{array}{l}622410917179510294405871731686106104901088942461831841974298796539766125460 \\
28110165477767 \\
483919214370492832647985133778825715105723659691035933111065010914565223100 \\
7611107263075422884480633359855258993445336838922751612084\end{array}$ \\
\hline
\end{tabular}

*Indicates that the best layout is the same as mentioned in [54]

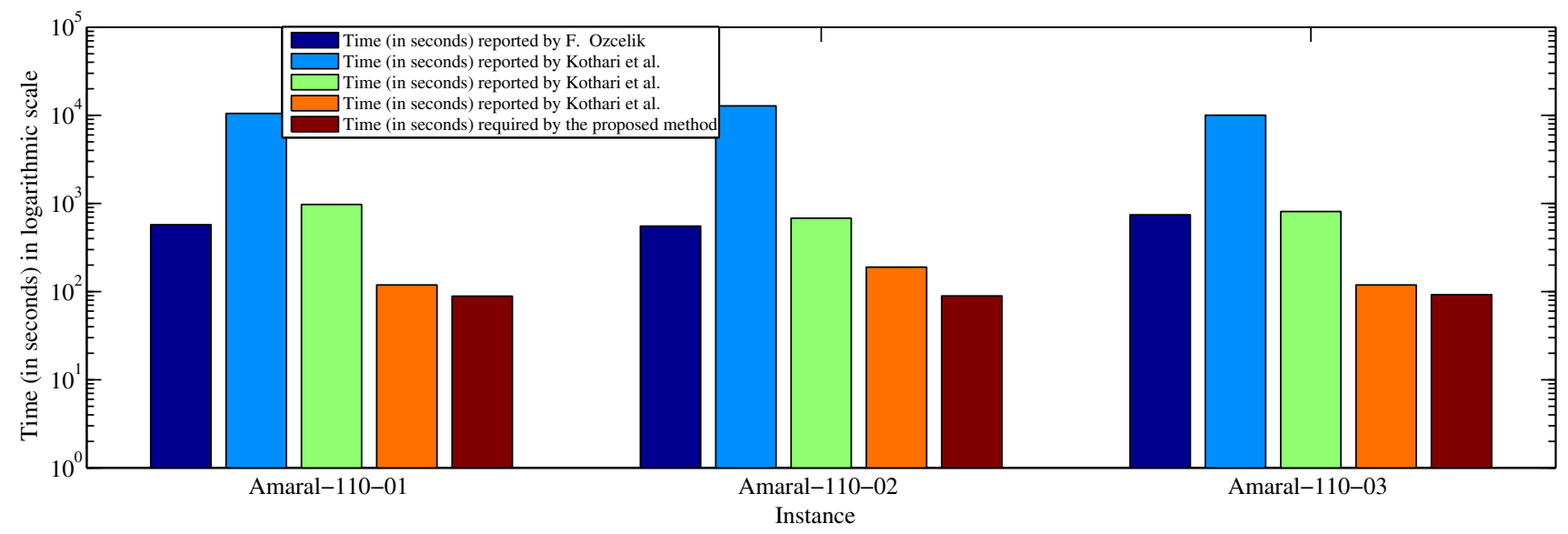

Figure 7. Performance comparison with Ozcelik [24] and Kothari and Ghosh [10, 13, 25] for Amaral instances $(n=110)($ see table 9).

taken from [54]. This set of large size SRFLP instances are used in $[15,26]$. Three insertion-based local search procedures have been developed by Palubeckis [26] and these local search procedures have been incorporated into a variable neighbourhood structure (VNS) to form different algorithms for solving large size SRFLP instances. In this article, we have compared the performance of the proposed algorithm for the larger instances of SRFLP to that of the best performing algorithm VNS-LS3 developed in [26]. We have set the parameter $\alpha$ to 5 while performing experiments on these large date sets to get the best cost mentioned in [26]. This eventually increased the computational time for our experiment. The computational results are given in table 11. Column 3 of table 11 gives the best cost obtained by running VNS-LS3 for $5 \mathrm{~h}$ [26]. The proposed algorithm also achieves the same best cost within reasonable computational time, as shown in table 11. In our experiment, we terminate the program execution for these 20 large size instances whenever it achieves the best cost obtained by VNS-LS3 as mentioned in [26]. The computational time required by the proposed algorithm for each of these large size instances is graphically compared with the time required by each of the methods proposed by Palubeckis [26] as shown in figure 8 . In table 12 , we present the best layouts corresponding to the best cost mentioned in table 11. It is to be noted that the best layouts for all the instances mentioned in table 12 are different from those given in [54], although the corresponding costs are the same. Further, note that we have considered two layouts as the same if they are reverse of each other. This indicates the existence of multiple layouts having the same cost and it is quite natural in any combinatorial optimization problem. 
Table 11. Performance comparison for large-scale SRFLP instances $(110 \leq n \leq 300)$.

\begin{tabular}{|c|c|c|c|c|c|}
\hline \multirow[b]{2}{*}{ Instance } & \multirow[b]{2}{*}{$n$} & \multirow[b]{2}{*}{$\operatorname{Cost}^{\mathrm{f}}$} & \multirow[b]{2}{*}{ Time $^{f}$} & \multicolumn{2}{|c|}{ Proposed heuristic } \\
\hline & & & & Cost & Time \\
\hline $\mathrm{p} 110$ & 110 & 4435868 & 5 & 4435868 & 3.3 \\
\hline p120 & 120 & 6282721 & 5 & 6282721 & 3.7 \\
\hline p130 & 130 & 7880929.5 & 5 & 7880929.5 & 3.8 \\
\hline p140 & 140 & 9257162 & 5 & 9257162 & 3.9 \\
\hline p150 & 150 & 10624389.5 & 5 & 10624389.5 & 4.2 \\
\hline p160 & 160 & 14873277 & 5 & 14873277 & 4.3 \\
\hline p170 & 170 & 16630187 & 5 & 16630187 & 4.3 \\
\hline p180 & 180 & 18746031.5 & 5 & 18746031.5 & 4.9 \\
\hline p190 & 190 & 24453272 & 5 & 24453272 & 4.7 \\
\hline p200 & 200 & 27482649.5 & 5 & 27482649.5 & 4.9 \\
\hline p210 & 210 & 29512000.5 & 5 & 29512000.5 & 4.4 \\
\hline p220 & 220 & 37351850.5 & 5 & 37351850.5 & 4.5 \\
\hline p230 & 230 & 46744886 & 5 & 46744886 & 4.5 \\
\hline p240 & 240 & 46717781 & 5 & 46717781 & 4.8 \\
\hline $\mathrm{p} 250$ & 250 & 54526293.5 & 5 & 54526293.5 & 4.8 \\
\hline p260 & 260 & 63300360.5 & 5 & 63300360.5 & 4.9 \\
\hline p270 & 270 & 68960438.5 & 5 & 68960438.5 & 5.1 \\
\hline p280 & 280 & 73845821 & 5 & 73845821 & 5.1 \\
\hline p290 & 290 & 86255267.5 & 5 & 86255267.5 & 5.4 \\
\hline p300 & 300 & 95937735 & 5 & 95937735 & 5.7 \\
\hline
\end{tabular}

${ }^{\mathrm{f}}$ Refers to the results reported in [26]

'Time' indicates the computational time in hours

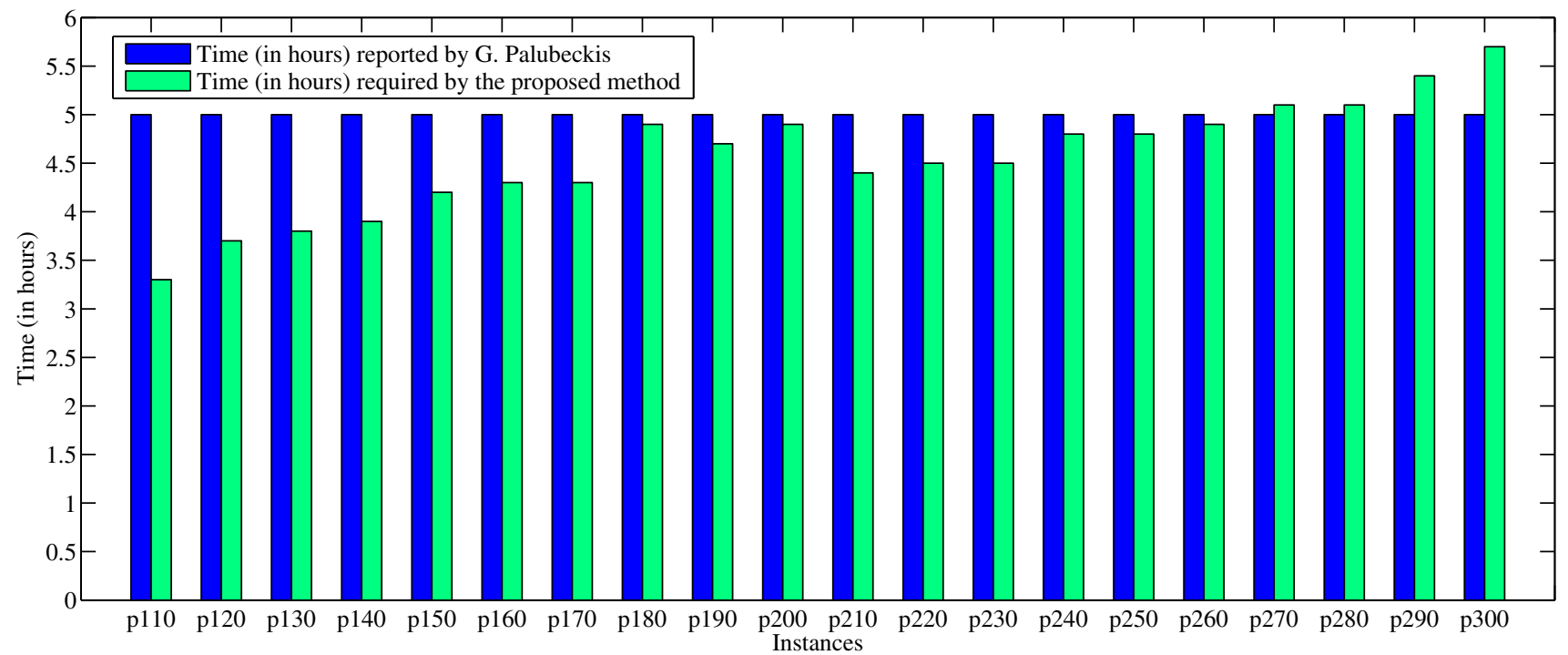

Figure 8. Performance comparison with Palubeckis [26] for large-scale SRFLP instances $(110 \leq n \leq 300)$ (see table 11). 
Table 12. Best layouts obtained for large-scale SRFLP instances $(110 \leq n \leq 300)$.

\begin{tabular}{|c|c|}
\hline Instance & Best layout \\
\hline p110 & $\begin{array}{l}972043038639410310950796259708385344711191008638998271694528447681711075346142273 \\
101367956486537102128762922684996625429010632618013155235621511049158931074395541 \\
437282161103329887796017675710578647540108315546823244995188\end{array}$ \\
\hline p120 & $\begin{array}{l}109499115923579118110849746123224046841105198349137121010496318556874426451176015 \\
621001141168610511339641482904253213671711829361694387310169805952335410272956619 \\
10771832168936398857057281191119755648328843508975257665305810647781312427103777 \\
1124112020\end{array}$ \\
\hline p130 & $\begin{array}{l}1131223599777123117391011144712956667944191212479241299226111167699406680908283126 \\
5730461720141217486186451125510684125356572951051022464127281331107381289370688125 \\
6052749638710813096109341195816182333911101031151512085321111008945494485104752169 \\
423722537343516227198718836118105078\end{array}$ \\
\hline p140 & $\begin{array}{l}68109116481366618691139323413319137867911994111321143577476140311105349911011072022 \\
8424305859138111130127402691337159711811712445921317812865120121331652642123508271 \\
1004251104981012546822875513981609510399551067370141023685639077410525121295412317 \\
62108381354129713980115964312672689568736761112578344883247134122\end{array}$ \\
\hline p150 & $\begin{array}{l}55544578645838584601101031462021512742581261494914713467915067749673144332413712047 \\
9756591412817514852483891653213913281232911282261672114313013114012986371111084068 \\
6113870991711396613530128393512271004487711199231071259510410211898271021896293114 \\
53506376771361161331158846811718121414199410612133451251243622142101691099014331105 \\
123141458057\end{array}$ \\
\hline p160 & $\begin{array}{l}78142120107681091087972151160731061342143111448155192562953311113611910150851122124 \\
27158403935103913791376114344102129181351011576311013960466501472311214813011541105 \\
56127821219965104559114116154921287196704854714111898511401332820291387680152613232 \\
8316894658139469126113499030248467429315226447117571259713138871533431275861003153 \\
36888155149175214515614612314264574159277\end{array}$ \\
\hline p170 & $\begin{array}{l}15111013111461368154296889194146541774890887129737599813415610872209914811713615724 \\
513711116915823709216017011189315360127814558421067455251033236641916214122116102163 \\
79161279613312846164124143130823031719780756269109491202127479107101138614114012621 \\
1750112152521326373 \quad 341471131501441198341 \quad 16514310412376386515910010663913915522 \\
95351671688116633118564410526135165121285311584894138674585149142155740125\end{array}$ \\
\hline p180 & $\begin{array}{l}1114012813215013692137142109163545116599313363661781668211317529698891151701623717749 \\
26160241531381673279559149841121571141836484791271425124108321201915213961169123148 \\
5089308398866544119125103156931261311312317452878341291551227926858561791704110480 \\
11517718110010267487641591414677151451061171725349711077510560118121471431761719038 \\
5588510716411645133135432294401216772215713015416762134168144146180425239161102076 \\
11135961581731013\end{array}$ \\
\hline p190 & $\begin{array}{l}9647391418753182499183168622186109180901561593017614614841371021616510491314534150 \\
122521271105722101153741216344489216615483358710167331571231791451331881531251347789 \\
758123189186172199113658325516713149137141462813513973381718288108151841441512078105 \\
15193654681077111770316042856463791909817111381756616973615276103173431818025512640 \\
1786920185147116119158726821741621321211429511812610611124111229100549713012894 \\
11217011456160164611611771401291552750845913814349\end{array}$ \\
\hline p200 & $\begin{array}{l}136751761024889175215517719760161115414910955351251521171499161506810371145158111181 \\
19696184511651391561428310070122151190371593245148872549248419282719861281356257185 \\
12167110415490113441051081071288826131121291341411061469383618013331911261448018786 \\
140825204316318614710411515720092150341017876227421641718579771796642196137118182187 \\
194160124231301741705813816233183195647216881188131123934532918911917547166951147397 \\
59401271323911698783019931916911012117256169153461206717315121193143946365\end{array}$ \\
\hline p210 & $\begin{array}{l}140941014583981873951339012351621041912310955220761170206201691665726124320519620471 \\
277313714316415261091722081061029118513113611960845475665963671105531978119417122103 \\
17813881881919229340234816534111751321687174180438210815817313986111115193142105160 \\
125371381841167415315717919824195144786414514177202118114494134155177018217792011811 \\
3072151201835320944168146112186181471561216911756135891131282550203176133382008149199 \\
32210189163154681671594128852980197148799676141503616147461221296221100130192127 \\
1079975651261515842190\end{array}$ \\
\hline
\end{tabular}


Table 12 continued

\begin{tabular}{|c|c|}
\hline Instance & Best layout \\
\hline p220 & $\begin{array}{l}2021712214589212962081111668819329941431799914183123219198180121024218171842071657115 \\
619200132151119112185169681361419177341101611571781181131092664195121108571761052756 \\
72197138114158412101624716342206199597916415013718491167177134415414218818713918615250 \\
220661611655672516858202817630862852612155317124216209781117282213634018100133310444 \\
2111701026911712543374975221491552031603921337410717456219880103851483132927023895 \\
1812016517513136713517310121413939754451834610618912015914087604812673212951 \\
1941153813015335205147144912820415690196190192127146182\end{array}$ \\
\hline p230 & $\begin{array}{l}1811512242005944220182189125223319722919978201192231508194127496159841831682120914858 \\
128731432106899198115710494114121311746477129162213172191861232052832193141124809538 \\
1371402031761132124133146147118163541772233937132202514916122115213810274432555153215 \\
90982148236756583130201792261452797662305213186228141962164610517318017822215413634 \\
195106119166170169101187227482197912221122511719821718420891457119671719015160109131 \\
505718513420417135101614463285155711881267210314293301212011010787419288116347182662 \\
89115296040165139164207218761965142175241351581121001565320616711110861695670\end{array}$ \\
\hline p240 & 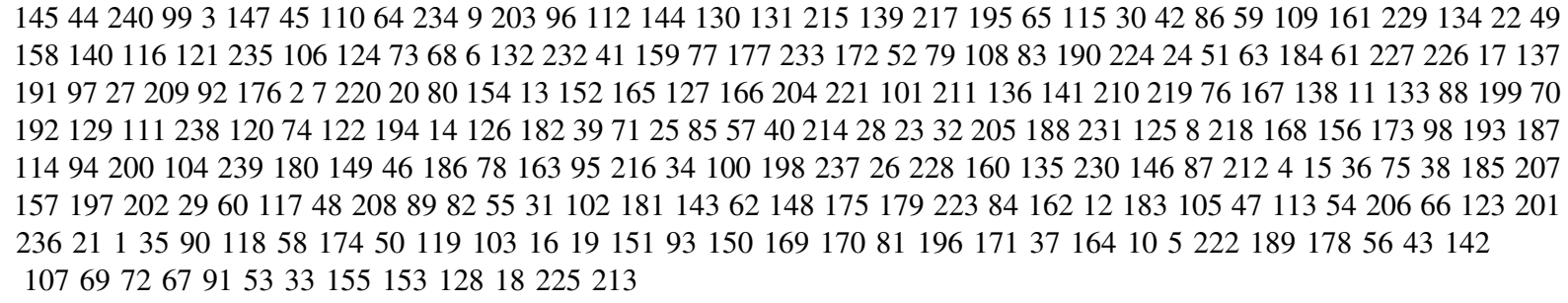 \\
\hline p250 & $\begin{array}{l}49225281412461161871302222119234184155612092407212373236144250761539614270119710247 \\
193146269137299581210238220224233221206632220113414059196182195681381611066160117424 \\
87572142321101768620017017413311851685815638244173213831216611011281672564142313612 \\
113674824521540177791810513720215799852391001141782379435217712774771476524721693562 \\
2051911391221991521653218152108179541643023518912542158120105519421243166320814812784 \\
331501691321909251124183103312481048921918621211114545223107180197241531983911188143 \\
1311388207341261997154174311522815950159823062754469172822291361711858090109175151 \\
162162322621882422271356011212914978204619220316324920441\end{array}$ \\
\hline p260 & $\begin{array}{l}1411802648260222258165292291535723324596250185332295533525712110311115120816814487143 \\
1881132432201556720956239150238232886213643151381489179210134174142451974121711217255 \\
101132752252231621227819315925511574128120198237915437160205182012111894145826020204 \\
5159140401021921218710324718619522530227127170133108226106114722411670139218166167110 \\
20015211825123023417323523761206156248492025065192991902241723610973831291961711755269 \\
10722820725619321413566164215816137131258936389724621621310520324798676240519925486 \\
6812414123126779221980811777158130119131194341691042312146147249244163146712429016154 \\
183121821842529424111149100842592731582863422531781918564181157176391179144 \\
2213\end{array}$ \\
\hline p270 & $\begin{array}{r}45271391281941846834923316218815653122124238186175102120842672139641229110107157131176 \\
373025016922215285198227266882231310920531103697513012230268256258142244159231134164 \\
173220393200362072282112522624314246203154264254161112178251237182111402061969333232 \\
218381937224015022574187816119026335148236189214133212571131581802249025362055261242 \\
2391354219216345023571179252177171146416870871324766118202241208106808914763265160217 \\
799419915514925924523100971971959519646014377115216251851741441671112015678209163886 \\
165101221591293211424714111712352919143913640106816615162715312158257170481524249116 \\
1522617228104448265184991385413751215172111819273145677626211912721098255222 \\
10591108126270234219248204260269183\end{array}$ \\
\hline p280 & $\begin{array}{l}243197631952718595852487325418119026110452182221238238126217123198309416679163234279 \\
2041216431231192362051118356106156205522725615811417620311019912462971362622423520260 \\
442701464823112292455453893987209292582501841471891451001288818812122814171729924149 \\
1071272692571314626282306874174232612131481871515016811715718658196129249221342201666 \\
2112763313990135962142061671372802194920124278194111141713102221601254786218424027734 \\
7191138244165264271265193175103652551925910118016211617064260914422680215320021670233 \\
1817232102526617920811817715526315224781267158322526810593177154218120672533611376159 \\
16115013042782595191982106140275173142282072522738225124637229109401081125769 \\
21227225431433524515322313313216923717175422741152391924117841\end{array}$ \\
\hline
\end{tabular}


Table 12 continued

\begin{tabular}{ll}
\hline Instance & Best layout \\
\hline p290 & 265362785110058341921515429028717627117014159243171424514328518085801181442242486467 \\
& 117125551021561212118200223281252214782095275289226242331473296921815757101150139140 \\
& 1223116718825527922116028638417427673158137232246266951137522715316225264148230146109 \\
& 242311071712042162471732748219121028442921457698277132504121218613418227210322963205 \\
& 1556524917777152288213261104461241082731966568112325997623189392631332401799011621715 \\
& 2704516925011022835711382151261202694819013523561237111062541545379130941594925670268 \\
& 2621051999130257296819519322016625162164601327225202258962614224114912012818311493260 \\
& 11212782398812944161083218711916523419720613699244168115283203219163404311122228089 \\
& 21120120816118747131842332286172198194717828196282207238721842361752671852535218137 \\
& 3742 \\
16242107295331717529928829617122612115296324920672293203195120102272158131267213291281 \\
& 12218120819323923027376917874259751636111315926627422781412511217276119441833736262 \\
& 1482838717417818821614141197269504710121114526421225105286294270289173198126341094538 \\
& 311902092012620424446225211532822216616571233242682571611827157169661541364172256139 \\
& 2921141111675618449177229116891621506785118284124221152149772982512021282231481401557 \\
& 68285247948660622379219651432318019254224275290985823413082102412845119183881561328 \\
& 2552409200261147512120731821381351442059359185246323026024512911742248189100701761997 \\
& 218127232179201601511339625028215525426510623569103552871087318023280170253277142186 \\
& 18727112316427829711213679263904325258300215243953935137146196622971942192384016814
\end{tabular}

\section{Conclusion}

In this article, we have proposed a population-based improvement heuristic with local search for solving SRFLP. The proposed heuristic approach utilizes some local search techniques and improvement strategies during each iteration for faster convergence of the solution. The proposed heuristic works well also for solving the SREFLP. The performance of the proposed algorithm has been demonstrated on several benchmark data sets and its performance has been compared to those of existing exact algorithms based on mathematical programming as well as meta-heuristic approaches. The proposed algorithm has achieved the best known results for all the instances considered in this article and the computational time is reasonably comparable to the time mentioned in the literature.

\section{Acknowledgements}

P R S Mahapatra, second author of this article, has been partially supported by DST-PURSE scheme, Government of India, at University of Kalyani.

\section{References}

[1] Simmons D M 1969 One-dimensional space allocation: an ordering algorithm. Oper. Res. 17(5): 812-826

[2] Picard J-C and Queyranne M 1981 On the one-dimensional space allocation problem. Oper. Res. 29(2): 371-391
[3] Beghin-Picavet M and Hansen P 1982 Deux problèmes d'affectation non linéaires. RAIRO-Oper. Res. 16(3): 263-276

[4] Heragu S S and Kusiak A 1988 Machine layout problem in flexible manufacturing systems. Oper. Res. 36(2): 258-268

[5] Suryanarayanan J K, Golden B L and Wang Q 1991 A new heuristic for the linear placement problem. Comput. Oper. Res. 18(3): 255-262

[6] Díaz J, Petit J and Serna M 2002 A survey of graph layout problems. ACM Comput. Surv. (CSUR) 34(3): 313-356

[7] Anjos M F and Yen G 2009 Provably near-optimal solutions for very large single-row facility layout problems. Optim. Methods Softw. 24(4-5): 805-817

[8] Datta D, Amaral A R S and Figueira J R 2011 Single row facility layout problem using a permutation-based genetic algorithm. Eur. J. Oper. Res. 213(2): 388-394

[9] Kothari Ravi and Ghosh Diptesh 2012 The single row facility layout problem: state of the art. Opsearch. 49(4): $442-462$

[10] Kothari R and Ghosh D 2013 Insertion based Lin-Kernighan heuristic for single row facility layout. Comput. Oper. Res. 40(1): 129-136

[11] Amaral A R S and Letchford A N 2013 A polyhedral approach to the single row facility layout problem. Math. Program. 141(1-2): 453-477

[12] Kothari R and Ghosh D 2013 Tabu search for the single row facility layout problem using exhaustive 2-opt and insertion neighborhoods. Eur. J. Oper. Res. 224(1): 93-100

[13] Kothari R and Ghosh D 2014 An efficient genetic algorithm for single row facility layout. Optim. Lett. 8(2): 679-690

[14] Hungerländer P 2014 Single-row equidistant facility layout as a special case of single-row facility layout. Int. J. Prod. Res. 52(5): 1257-1268 
[15] Palubeckis G 2015 Fast simulated annealing for single-row equidistant facility layout. Appl. Math. Comput. 263: 287-301

[16] Sarker B R, Wilhelm W E and Hogg G L 1998 Onedimensional machine location problems in a multi-product flowline with equidistant locations. Eur. J. Oper. Res. 105(3): 401-426

[17] Yu J, Sarker B R 2003 Directional decomposition heuristic for a linear machine-cell location problem. Eur. J. Oper. Res. 149(1): 142-184

[18] Anjos M F and Liers F 2012 Global approaches for facility layout and VLSI floorplanning. In: Handbook on Semidefinite, Conic and Polynomial Optimization, pp 849-877. Springer, Berlin

[19] Hungerländer P and Rendl F 2013 A computational study and survey of methods for the single-row facility layout problem. Comput. Optim. Appl. 55(1): 1-20

[20] Keller B and Buscher U 2015 Single row layout models. Eur. J. Oper. Res. 245(3): 629-644

[21] Anjos M F and Vieira M V C 2017 Mathematical optimization approaches for facility layout problems: the state-of-theart and future research directions. Eur. J. Oper. Res. 261(1): $1-16$

[22] Hungerländer P and Rendl F 2013 Semidefinite relaxations of ordering problems. Math. Program. 140(1): 77-97

[23] Palubeckis G 2012 A branch-and-bound algorithm for the single-row equidistant facility layout problem. OR Spectr. 34(1): 1-21

[24] Ozcelik F 2012 A hybrid genetic algorithm for the single row layout problem. Int. J. Prod. Res. 50(20): 5872-5886

[25] Kothari R and Ghosh D 2014 A scatter search algorithm for the single row facility layout problem. J. Heuristics 20(2): 125-142

[26] Palubeckis G 2015 Fast local search for single row facility layout. Eur. J. Oper. Res. 246(3): 800-814

[27] Atta S, Mahapatra P R S and Mukhopadhyay A 2018 Solving maximal covering location problem using genetic algorithm with local refinement. Soft Comput. 22(12): 3891-3906

[28] Atta S, Mahapatra P R S and Mukhopadhyay A 2018 Deterministic and randomized heuristic algorithms for uncapacitated facility location problem. In: Information and Decision Sciences, pp. 205-216. Springer, Berlin

[29] Atta S, Mahapatra P R S and Mukhopadhyay A 2018 Solving uncapacitated facility location problem using monkey algorithm. In: Intelligent Engineering Informatics, pp. 71-78. Springer, Berlin

[30] Atta S, Mahapatra P R S and Mukhopadhyay A 2019 Multiobjective uncapacitated facility location problem with customers preferences: Pareto-based and weighted sum gabased approaches. Soft Comput.. https://doi.org/10.1007/ s00500-019-03774-1

[31] Atta S, Mahapatra P R S and Mukhopadhyay A 2019 Solving uncapacitated facility location problem using heuristic algorithms. Int. J. Nat. Comput. Res. (IJNCR) 8(2): 18-50

[32] Atta S, Sinha Mahapatra P R and Mukhopadhyay A 2019 Solving tool indexing problem using harmony search algorithm with harmony refinement. Soft Comput. 23(16): 7407-7423

[33] Love R and Wong J 1976 On solving a one-dimensional space allocation problem with integer programming. INFOR: Inf. Syst. Oper. Res. 14(2): 139-143
[34] Heragu S S and Kusiak A 1991 Efficient models for the facility layout problem. Eur. J. Oper. Res. 53(1): 1-13

[35] Amaral A R S 2006 On the exact solution of a facility layout problem. Eur. J. Oper. Res. 173(2): 508-518

[36] Amaral A R S 2008 An exact approach to the onedimensional facility layout problem. Oper. Res. 56(4): 1026-1033

[37] Amaral A R S 2009 A new lower bound for the single row facility layout problem. Discrete Appl. Math. 157(1): $183-190$

[38] Anjos M F, Kennings A and Vannelli A 2005 A semidefinite optimization approach for the single-row layout problem with unequal dimensions. Discrete Optim. 2(2): 113-122

[39] Anjos M F and Vannelli A 2008 Computing globally optimal solutions for single-row layout problems using semidefinite programming and cutting planes. INFORMS J. Comput. 20(4): 611-617

[40] Sanjeevi S and Kianfar K 2010 A polyhedral study of triplet formulation for single row facility layout problem. Discrete Appl. Math. 158(16): 1861-1867

[41] Djellab H and Gourgand M 2001 A new heuristic procedure for the single-row facility layout problem. Int. J. Comput. Integr. Manuf. 14(3): 270-280

[42] Kumar K R, Hadjinicola G C and Lin T 1995 A heuristic procedure for the single-row facility layout problem. Eur. J. Oper. Res. 87(1): 65-73

[43] de Alvarenga A G, Negreiros-Gomes F J et al 2000 Metaheuristic methods for a class of the facility layout problem. J. Intell. Manuf. 11(4): 421-430

[44] Samarghandi H and Eshghi K 2010 An efficient tabu algorithm for the single row facility layout problem. Eur. J. Oper. Res. 205(1): 98-105

[45] Romero D, Sánchez-Flores A 1990 Methods for the onedimensional space allocation problem. Comput. Oper. Res. 17(5): 465-473

[46] Heragu S S and Alfa A S 1992 Experimental analysis of simulated annealing based algorithms for the layout problem. Eur. J. Oper. Res. 57(2): 190-202

[47] Solimanpur M, Vrat P and Shankar R 2005 An ant algorithm for the single row layout problem in flexible manufacturing systems. Comput. Oper. Res. 32(3): 583-598

[48] Satheesh K R M, Asokan P, Kumanan S and Varma B 2008 Scatter search algorithm for single row layout problem in FMS. Adv. Prod. Eng. Manag. 3: 193-204

[49] Samarghandi H, Taabayan P and Jahantigh F F 2010 A particle swarm optimization for the single row facility layout problem. Comput. Ind. Eng. 58(4): 529-534

[50] Ficko M, Brezocnik M and Balic J 2004 Designing the layout of single-and multiple-rows flexible manufacturing system by genetic algorithms. J. Mater. Process. Technol. 157: $150-158$

[51] Rubio-Sánchez M, Gallego M, Gortázar F and Duarte A 2016 GRASP with path relinking for the single row facility layout problem. Knowl.-Based Syst. 106: 1-13

[52] Teo Y T and Ponnambalam S G 2008 A hybrid ACO/ PSO heuristic to solve single row layout problem. In: IEEE International Conference on Automation Science and Engineering, 2008. CASE 2008. IEEE, pp. 597-602

[53] Kunlei L, Chaoyong Z, Liang G and Xinyu S 1995 Single row facility layout problem using an imperialist competitive 
algorithm. In: Proceedings of the 41st International Conference on Computers \& Industrial Engineering

[54] Palubeckis G 2013 Single row facility layout. https://www. personalas.ktu.lt/ ginpalu/srflp.html

[55] Obata T 1979 Quadratic assignment problem: evaluation of exact and heuristic algorithms. Ph.D. thesis

[56] Sarker B R 1990 The amoebic matrix and one-dimensional machine location problems. J. Oper. Manag. 9(3): 439-440

[57] Nugent C E, Vollmann T E and Ruml J 1968 An experimental comparison of techniques for the assignment of facilities to locations experimental comparison of techniques for the assignment of facilities to locations. Oper. Res. 16(1): 150-173

[58] Skorin-Kapov J 1990 Tabu search applied to the quadratic assignment problem. ORSA J. Comput. 2(1): 33-45

[59] Loiola E M, de Abreu N M M, Boaventura-Netto P O, Hahn $\mathrm{P}$ and Querido T 2007 A survey for the quadratic assignment problem. Eur. J. Oper. Res. 176(2): 657-690

[60] Letchford A N and Amaral A 2011 A polyhedral approach to the single row facility layout problem. Technical Report 49043, The Department of Management Science, Lancaster University 